Teología y Vida, Vol. XLVI (2005), 321 - 351

Jorge Costadoat C., S.J.

Profesor de la Facultad de Teología

Pontificia Universidad Católica de Chile

\title{
Pietas et eruditio en Alberto Hurtado, S.J.
}

\author{
"La ciencia y la piedad son los ojos espirituales del sacerdote. \\ El que carece de uno, tuerto; el que de ambos, ciego" (1).
}

Con motivo de la canonización del padre Alberto Hurtado, S.J., este artículo pretende decir una palabra sobre un aspecto poco estudiado de su personalidad. Se ha escrito sobre su vocación social e incluso sobre su espiritualidad. Ha faltado, en cambio, algún estudio sobre la estatura intelectual de Hurtado. Aquí se hará a propósito de la estrecha relación entre su espiritualidad y su prestancia intelectual.

Antes de entrar derechamente en materia, conviene advertir que nos acercamos al pensamiento de Alberto Hurtado a través de sus escritos, pero también observando el impacto institucional en la Compañía de Jesús, su repercusión en una generación completa de jesuitas de excepción y en sus propias obras. El P. Hurtado no ha sido un reformador, pero sí un refundador de la Compañía de Jesús en Chile. Aunque el punto merezca investigación aparte, sobran los datos para creer que Hurtado reinterpretó a fondo el carisma ignaciano, plasmándolo en variadas obras y trasmitiendo a la provincia jesuita chilena una orientación duradera. Por esta razón se aprovechan en este artículo impresiones personales del santo que llegan hasta nosotros como eco aún cercano y, por otra parte, no desechamos materiales escritos suyos incompletos, redactados a la carrera, telegráficos, esquemáticos, que evaluamos con cautela.

Abordamos este tema, además, en días en que la imagen pública del santo es la del sacerdote caritativo que fundó el Hogar de Cristo. Sería inútil pretender sustituir una imagen de Hurtado por otra, más aún tratándose de un hombre cuya obra principal es considerada marca nacional. Con Alberto Hurtado ha sucedido algo poco frecuente entre los santos de la Compañía de Jesús. Él goza de popularidad no por ser un sacerdote jesuita, sino por ser un sacerdote chileno que recogió a los niños pobres. El estudio de su figura intelectual enmarca esta imagen en su verdadero alcance. Aún se escucha que el Padre Hurtado habría dicho que, de haber habido justicia en Chile, no hubiera sido necesario fundar el Hogar de Cristo. Ha sido

(1) S40 y 11. Esta numeración corresponde al archivo de escritos y documentos del P. Hurtado, digitado y ordenado por el P. Samuel Fernández. 
precisamente la ilustración del jesuita la que le ha hecho consciente acerca de los problemas estructurales de la generación de la miseria, y la que le ha empujado a abrir otras obras, algunas de impacto intelectual directo como la revista Mensaje. Hurtado leyó, estudió y escribió con el propósito de atacar la pobreza en sus causas y no solo para aliviar su penosa realidad.

La interpretación de Hurtado está en juego. En el extremo de las posibilidades, pero como una apropiación que se aparta ya por completo de una interpretación legítima, el padre Hurtado compite en la devoción popular entre las pulseras, las estampas y los poderes milagrosos. ¿Habría aceptado el santo que, después de muerto, se hiciera un santuario en su memoria? Difícil, a no ser que se le hubiera asegurado que en este la pastoral propiciaría el encuentro con Cristo y la edificación de un país más justo. Hurtado es un apóstol ilustrado que no se resigna al sincretismo de la piedad popular, menos todavía a un catolicismo de etiqueta, pero es un jesuita que no se complica con "alabar candelas" (2), si ello no impide la evangelización auténtica. Pues bien, este artículo se escribe cuando la interpretación de Hurtado exige mostrar de él una aspecto cuyo olvido amenaza con desfigurarlo gravemente. En otra oportunidad he querido probar que la originalidad de la espiritualidad de Alberto Hurtado consiste en su "mística social" (3). En este afirmo que la pietas apostólica típicamente ignaciana, es la matriz de su "mística social" y de la eruditio que la sostiene. El contacto de Hurtado con el Cristo pobre es una experiencia indisociable de su cruzada por transformar la sociedad en su conjunto. Nuestro santo tiene cultura suficiente como para concebir la unidad social en términos de utopía y de creatividad, de conflicto y de reconciliación.

En suma, el discernimiento de la figura intelectual de Hurtado es necesario para desentrañar el misterio de su pietas, y viceversa.

\section{PIETAS ET ERUDITIO EN LOS JESUITAS}

Al aproximarse al misterio de la vida de un santo, es fácil equivocarse y retener como principal aquello que, siendo secundario, brilla en él como no ocurre en otros. Para evitar este error al acercarnos a Alberto Hurtado, es necesario conocer algo de las coordenadas teóricas y espirituales que hicieron posible el desarrollo de su cristianismo. Es indispensable, por tanto, recordar el modo ignaciano de la articulación de pietas et eruditio.

Ignacio de Loyola y sus primeros compañeros estudiaron filosofía y teología en París en tiempos de enorme ebullición intelectual y teológica, y de sacudimientos históricos y eclesiales que abrieron una nueva época. Ha sido anacrónico dar mucha

(2) Ejercicios Espirituales, $\mathrm{N}^{\mathrm{o}} 358$

(3) La expresión "mística social" no es de Alberto Hurtado. Con ella he querido denominar la originalidad de su espiritualidad (cf. J. Costadoat "La 'mística social' del Padre Hurtado", Teología y Vida, Vol. XXXVII (1996), pp. 279-292). Sin embargo, el objeto de Humanismo Social de Alberto Hurtado es, en sus propias palabras, un "ensayo de pedagogía social" que pueda despertar en el alma de los católicos "una mística del sentido social" (Cf. Humanismo social, Editorial Salesiana, 1984, p. 118), que anime la acción transformadora de la sociedad en su conjunto. 
importancia a la participación de los primeros jesuitas en las discordias de entonces. Solo después de muerto Ignacio, una vez acrecentada su figura, se lo opuso a Lutero y se dijo, por ejemplo, que la Compañía de Jesús había sido fundada para enfrentar al protestantismo (4). Llama la atención, con todo, que los primeros compañeros no hayan desempeñado un papel relevante en los conflictos en torno a la Facultad de Teología de París. Si entonces eran más bien los humanistas los que agitaban ese ambiente, según Peter-Hans Kolvenbach, actual P. General de la Compañía de Jesús, "no parece que Ignacio y sus compañeros hicieran plenamente suyas esas luchas", por una razón muy particular: "les movía otra pietas que la pietas temerosa y amenazada de los teólogos 'ortodoxos'; y su pietas necesitaba mucho menos defenderse de las aportaciones de la eruditio que el nominalismo escolástico, al cual preferían ya ellos el pensamiento mucho más equilibrado, más abierto y más vivo de Santo Tomás..." (5). Eran solo estudiantes, cierto. Pero no los movía una causa inmediatamente teórica tampoco, sino una espiritual y práctica. Guiados por Ignacio, los jesuitas de París fueron marcados por los Ejercicios Espirituales que los inició en un tipo de experiencia de Dios en la que ellos a su vez quisieron iniciar a otros.

Esta disposición inicial, espiritual y práctica, germinal aunque bien determinada, probablemente preparó a Ignacio y a sus compañeros para abrirse sin temor a las diversas posturas en tensión. Consta que recibieron su formación de los cuatro colegios de París, es decir, de las diversas tendencias, sin abanderizarse con ninguna de ellas. Las aprovecharon todas. En ellos parece haber predominado un cierto eclecticismo, que solo la división de la cristiandad subsecuente obligó a arrinconar más por razones eclesiales que por móviles estrictamente teológicos (6). Pero los primeros jesuitas no fueron enrolados en la defensa escolástica y pietista que Noel Beda, decano de la Facultad de Teología, libraba contra el humanismo renacentista y en especial el humanismo cristiano de Lefèvre d'Étaples. Por el contrario, los estudiantes jesuitas de París tomaron de las diversas escuelas escolásticas sus mejores aportes con la misma libertad con que adoptaron la extraordinaria contribución que representaba el estudio de las lenguas clásicas para la interpretación de las Sagradas Escrituras, propiciado por Erasmo y los demás humanistas. Ellos experimentaron el mismo influjo que esos años despejaba el camino a la lectura luterana de la Biblia. Si la motivación principal de los primeros jesuitas no fue teológica sino espiritual y pastoral, ella supuso, sin embargo, una intuición teológica que la primera generación de jesuitas no elevó a concepto (7).

(4) Cf. John W. O’Malley Los primeros jesuitas, Ediciones Mensajero / Sal Terrae, Santander (en inglés, 1993), p. 341

(5) Peter-Hans Kolvebach Pietas et eruditio, Información S.J., No 104 (julio-agosto de 2004) pp. 116. Publicado originalmente en francés en Gregorianum, № 85, 2004.

(6) La acusación de "eclecticismo de ocasión" a la teología de los jesuitas, según Karl Rahner, algo tiene de válida, pero este "puede perfectamente expresar también el hecho de que el hombre se ve superado por la verdad de Dios y lo acepta dócilmente". Con ello rescata para los jesuitas su condición de teológos "peregrinos" en búsqueda de "la patria eterna de la verdad" (Palabras de Ignacio de Loyola a un jesuita de hoy, Cuadernos de espiritualidad ignaciana, Santiago de Chile, $\mathrm{N}^{\mathrm{o}} 10,1981$, p. 31.

(7) Llama la atención que hayan pasado siglos hasta que recién jesuitas como Erich Przywara, Gaston Fessard, los hermanos Rahner y Hans Urs von Balthasar, hayan indagado en la teología de los Ejercicios, descubriendo en ellos un nuevo modo de hacer teología. 
Como ha podido esclarecer el P. Kolvenbach, la eruditio ignaciana se engasta en una pietas apostólica. La fama mítica de cultos de los jesuitas es engañosa. Más de alguno ha podido imaginar que esta eruditio se busca por sí misma, independientemente de una experiencia espiritual y una motivación pastoral. Sucede al revés. Sin perjuicio de la gratuidad que todo estudio auténtico merece, en la espiritualidad ignaciana la eruditio extrae su razón última de ser de la contemplatio ad amorem (EE.EE. 230ss) que impulsa a Ignacio y compañeros colaborar en el anuncio que la Iglesia hace al mundo del Evangelio. Al recordar la génesis de la originalidad de la experiencia espiritual de san Ignacio, es posible advertir que a los tiempos de su conversión, cuando la intensidad de su encuentro con Dios fue más intensa, Iñigo cortó incluso con la refinada cultura de la corte del emperador que poco antes lo prestigiaba. El conocimiento interior de Dios le ha parecido bastar. Como dice el P. General del santo de esa época, "pietas y eruditio no hacen inmediatamente buenas migas" (8). En Ignacio se dará una recuperación y un redescubrimiento del valor de la ciencia y de la teología en particular, motivados por su afán de comunicar a otros su experiencia de Dios, haciéndolos entrar en esa relación única entre el Creador y su criatura que el acompañante en los Ejercicios debe facilitar al máximo. Por cierto la crueldad de la Inquisición le ayudó a entender que debía estudiar para sortear la acusación de "iluminado". Pero fue su deseo de "ser siempre más útil a las almas", y no un escrúpulo sobre la propia ortodoxia ni tampoco el miedo a su perseguidores, lo que le llevó a estudiar en Barcelona, Alcalá, Salamanca y en París.

El nuevo carisma que surgía en la Iglesia también forjó su novedad en el campo de la teología. Esta no estriba solamente en la presencia en Trento de algunos jesuitas como Laínez, Salmerón y Jayo. Tampoco en que la Compañía contara con un doctor en teología notable como Nadal. El resto estudió solo la teología suficiente y padeció la que denominaron teología "puramente especulativa" (9). Un modo escolástico y típicamente universitario de enseñar la teología, alejado de la realidad y poco espiritual, fue repetidamente criticado por ellos. Los jesuitas identificaron a la suya como "teología mística", aquí está la novedad. A saber, una teología espiritual que refería todas las cosas a Dios y a su gracia; una teología pensada con el corazón, que tocaba los afectos; una teología, en fin, práctica, orientada a ayudar a los demás (10). Esta "teología mística" llevó a que los jesuitas se consideraran ellos mismos teólogos y así fueran vistos por otros. En este sentido Nadal llama a Ignacio "el teólogo", siendo que entre los de la generación el santo no parece haber brillado por un dominio académico de la teología. La genialidad teológica de Ignacio ha sido eminentemente espiritual. Desde entonces hasta hoy, los estudiantes de la Compañía de Jesús se descubren a sí mismos haciendo teología al momento de dar a otras personas los Ejercicios Espirituales, cuando entran en contacto con sus dolores y esperanzas, las veces que descubren a Dios guiándolas amorosamente por caminos siempre originales. En las aulas universitarias, por el contrario, lamentan la misma desconexión que ya Erasmo denunciaba entre la teología y la espiritualidad.

(8) Kolvenbach, o.c., p. 114.

(9) Cf. O'Malley, o.c., p. 300.

(10) Cf. O’Malley, o.c., p. 309. 
En tanto eruditio, esta teología de los jesuitas no podía encerrar la verdad del mundo en un sistema acabado, sino que debía permanecer siempre abierta, como toda ciencia, a nuevos conocimientos. En cuanto pietas, por otra parte, la teología debía servir a las necesidades de la Iglesia y, por tanto, había de ser sólida, segura, circunspecta y vigilante de un bien universal (11). "En virtud de su doble relación con la pietas y la eruditio", piensa el P. Kolvenbach, esta teología ha podido conseguir "una fidelidad asegurada a la exposición de la fe y el tener en cuenta las realidades culturales y problemáticas propias de cada época. La teología tanto para los jesuitas como para los no jesuitas es así, una teología en la cual están aseguradas tanto la referencia a la fe eclesial como la referencia al mundo y a la cultura de hoy" (12). Su pietas no cerró a los jesuitas a contemplar a Dios a través de una teología "exclusivamente teológica". Los ha liberado, por el contrario, para adoptar sin temor cualquier instrumento, cualquier mediación científica, no una sino varias teologías que les permitan anunciar el Evangelio de un modo verdaderamente misionero, a un mundo siempre en cambio.

\section{CALIBRE INTELECTUAL DE HURTADO}

El trabajo intelectual en nuestro medio no goza siempre de prestigio. Se lo puede admirar, pero pocos tienen la disciplina para intentarlo. A veces se lo desprecia, porque en nuestra historia la "cultura" se ha usado para oprimir. En nuestras escuelas los estudiosos son ocasión de burla. Los latinoamericanos hemos dependido intelectualmente de Europa a lo largo de cinco siglos y hoy asimilamos sin mayor crítica lo que proviene de los EE.UU. Carecemos de una tradición contemplativa y reflexiva gratuita y propia de la fe cristiana. Entre nosotros, la propensión al activismo es un mal endémico (13).

Este problema merece en Hurtado una mínima pesquisa. Levantada en su caso la sospecha de inmediatismo que pesa sobre el clero latinoamericano, será posible justificar que él es un intelectual y, en particular, un intelectual conforme al patrón de los primeros jesuitas (14).

\section{a) Juicio sobre "lo intelectual"}

Dos son los campos semánticos principales en los cuales alude a la dimensión intelectual, a la actividad intelectual o a los intelectuales: uno es el del conocimiento

(11) Kolvenbach, o.c. pp. 119-120.

(12) Kolvenbach, o.c. p. 120.

(13) Cf. Juan Noemi, "Rasgos, imperativos y desafíos", en J. Noemi y F. Castillo Teología Latinoamericana, Centro Ecuménico Diego de Medellín, Santiago, 1998, p. 23.

(14) Acertadamente afirma de él el P. Samuel Fernández: “...resulta extremadamente significativo que, precisamente en nuestra Iglesia chilena, Iglesia marcada por una gran sensibilidad por las urgencias que la rodean y por ello acechada por la tentación del inmediatismo en la acción, uno de los sacerdotes cuyo ministerio pastoral ha sido tan fecundo, según nuestros pobres criterios de juicio, le haya dedicado tanto tiempo y con tanta seriedad a su formación teológica y, más en general, al estudio" ("Relación del Padre Alberto Hurtado, S.J., con la Facultad de Teología de la Pontificia Universidad Católica de Chile" (Teología y Vida, Vol. XLIV [2003], p. 18. 
humano y otro el de los pensadores sociales. En muchas ocasiones, y sobre todo en su tesis sobre Dewey, Alberto Hurtado se refiere a lo intelectual en la perspectiva psicológica del conocimiento humano y en el de su desarrollo. Cuánto ha podido influir Dewey en su propia manera de pensar, sería materia de una investigación aparte. De momento es posible advertir una profunda conexión entre la aproximación inductiva de Hurtado al conocimiento de la realidad y el Dewey posthegeliano que afirma contra viento y marea el carácter experimental y pragmático del conocimiento humano. Es probable que del mismo Dewey -no solo de sus profesores de Lovaina- haya sacado Hurtado algo de su aversión al dogmatismo, a la apologética tan orgullosa como inútil, al intelectualismo alejado de la realidad y de la praxis, a los conocimientos "librescos" de la vida y del mundo, y a la enseñanza memorística de la fe cristiana. En Hurtado prima la perspectiva integradora de lo cognitivo, lo afectivo, lo físico y lo artístico, a partir de una experiencia de Dios. En esto último, a diferencia de Dewey.

Hurtado valora la aproximación experiencial a la realidad. Desconfía de la deducción apriorística, pero no desecha la metafísica. Es más, critica a Dewey el agnosticismo de su sistema, en la misma medida que el experimentalismo descarta el valor enorme de la tradición y de la contemplación católica de la verdad en el conocimiento de Dios y del mundo. Para Hurtado el conocimiento religioso tiene un componente intelectual tradicional insuprimible (15) y, por lo mismo, lamenta profundamente la ignorancia que las mayorías católicas tienen de su fe. La valoración de la dimensión intelectual del catolicismo explica la inquietud de Hurtado en su obra ¿Es Chile un país católico? La falta de sacerdotes impide la enseñanza de la fe católica, y la elevación intelectual y moral del pueblo.

Si en el plano psicológico el P. Hurtado otorga a la dimensión intelectual un lugar clave en el desarrollo de la personalidad de los niños y de los adolescentes, la importancia que reconoce a los intelectuales en la sociedad es también enorme. Tiene una altísima estima de los intelectuales católicos de su época, los conoce y los cita con frecuencia. De los intelectuales en general, incluso de quienes no comparte sus ideas, es consciente de su gran influjo en la sociedad a través de sus ideas y de sus libros (16). Reacciona a su vez en contra de los intelectuales perdidos en su

(15) Afirma: "Una religión que no posee fundamentos intelectuales o racionales -poco importa la palabra que se emplee, con tal de que se acepte la idea de una justificación para las facultades superiores del hombre, las que nos ponen en contacto con la realidad y nos dan la certeza- para un católico no es una religión; un sentimiento, que no está basado sobre una tal creencia, podrá ser un sentimiento estético, poético..., pero no un sentimiento religioso. Es apenas necesario agregar que el conocimiento filosófico de Dios es muy imperfecto; es, sin embargo, suficiente para distinguir a Dios de las realidades distintas de Él" (Alberto Hurtado El sistema pedagógico de John Dewey ante las exigencias de la doctrina católica, Universidad Católica Blas Cañas [traducida por Jaime Caicedo], Santiago, 1994, p. 178).

(16) En sus propias palabras: "Hay quienes tienen cualidades extraordinarias para pensar, exponer, escribir y muchas veces no se encuentran bien en el terreno de las realizaciones. La acción intelectual es preciosa en la crítica de los defectos y en el estudio de soluciones sociales. A veces un escritor tiene más influencia que muchos realizadores: basta mirar a Kant, Marx, Nietzsche, o si se prefieren ver influencias luminosas, las de Kempis, Tomás de Aquino, Pedro Canisio, etcétera. Cada uno de nosotros ¡cuánta gratitud no debe a escritores que han ejercido poderosa influencia sobre su vida! Un libro para muchos ha sido la ocasión de descubrir su vocación a la fe, al sacerdocio, al apostolado social" (Humanismo Social, Editorial Salesiana, Santiago, 1984, p. 184). 
agnosticismo, incapaces de atender las demandas de pensamiento de los obreros. Su concepto del trabajo intelectual es amplio. Alcanza para llamar "intelectual" al servicio que algunos letrados deben prestar a los sindicalistas de la ASICH.

Hurtado es un promotor de la lectura, de la escritura, del apostolado y de la acción intelectual. No hay en él sombra de antiintelectualismo, pero critica todo modo de entender lo intelectual que aleje de la realidad.

\section{b) ¿Un intelectual o un hombre de acción?}

¿Fue Alberto Hurtado un intelectual o un hombre de acción? El planteamiento de esta pregunta nos ilumina en la medida que barajamos argumentos en pro y contra de una u otra posibilidad.

En contra de que haya sido un intelectual, habría que decir que un jesuita que en un período de ministerio sacerdotal muy breve funda varias obras y desempeña una cantidad de ocupaciones que ningún otro ha podido ejercer sino de modo excepcional, no ha tenido la calma que el estudio requiere. No parece tampoco que Alberto Hurtado haya hecho un aporte especial en el campo del pensamiento. Se podría decir que fue un sacerdote aggiornato, un difusor de las ideas sociales y teológicas de los papas y de la vanguardia de su época, que anticipó proféticamente temáticas que harían fortuna en las décadas sucesivas: la opción por los pobres de la Iglesia latinoamericana y tópicos característicos de la cristología de la liberación, como ser la centralidad del reino de Dios y de la acción. Sin embargo, el medio intelectual no lo recuerda entre los suyos.

Por otra parte, no se pueden pasar por alto datos que nos hablan de una inclinación de Alberto Hurtado por la ciencia y de una actividad que solo un intelectual puede emprender. No cualquier sacerdote, y menos en su época, tuvo estudios tan largos: antes de entrar en la Compañía de Jesús se tituló de abogado; estudió luego Filosofía y Teología; y finalmente se doctoró en Educación. Fue consultado para la contratación de profesores de la Facultad de Teología de la Universidad Católica, a efectos de lo cual debió visitar los principales centros europeos de educación superior, entrevistarse con las máximas autoridades y juzgar críticamente la idoneidad de numerosos teólogos. De vuelta en Chile enseñó un tiempo en Pedagogía, Derecho y Arquitectura, se le invitó a dar charlas a la universidad y opinó sobre esta con propiedad. Participó en las Semanas Sociales en París. Conoció la literatura contemporánea. Creó la Acción Sindical Chilena, para la formación de los sindicalistas. Fundó la revista Mensaje para elevar la condición intelectual de los católicos chilenos. Y, por cuenta propia, escribió doce libros. Estos ubican a Hurtado entre los escasos sacerdotes que en su época publicaron alguna vez un libro. Hay también informaciones candorosas que he podido comprobar personalmente. Jesuitas que vivieron con él recuerdan que tras la puerta de su habitación se le escuchaba siempre teclear sobre su máquina de escribir y que a vacaciones iba con un "maleta de libros" para leer o consultar.

El testimonio que Alvaro Lavín, su amigo y provincial, ofrece del brinco intelectual que Hurtado da en Lovaina, es elocuente: "aquí, en Lovaina, y especialmente en sus estudios teológicos fue cuando... comenzó a dar muestras muy claras de su gran capacidad intelectual. Como ya dije, en sus estudios secundarios fue un alumno 
bueno, pero corriente; en la universidad sus estudios fueron, sin duda, muy buenos y coronados por el éxito y las buenas notas, pero las preocupaciones económicas y familiares fueron inevitablemente un escollo para alcanzar una mayor profundidad y brillo. En cambio, en Lovaina fue muy buen alumno y llamó la atención. Lo digo, porque para mí, que lo conocí y traté tanto, fue una sorpresa desde entonces $-\mathrm{y}$ mayor cada día- el verlo de una agilidad mental muy grande y capaz de captar bien las constantes novedades ideológicas y culturales; sorpresa que he considerado siempre solo explicable por una ayuda especial de Nuestro Señor" (17).

La respuesta al interrogante planteado dependerá, por cierto, de qué se entienda por intelectual. Alberto Hurtado no fue un universitario dedicado en cuerpo y alma a su disciplina, a la docencia y a la investigación. Dio algunos cursos en la universidad y en el Seminario Pontificio, y terminó por apartarse de la enseñanza de nivel universitario. Es cierto que la actividad académica caracteriza a la mayoría de los intelectuales. Sin embargo, buena parte del trabajo intelectual hoy se realiza a través de sus publicaciones y en el foro de los medios de comunicación social. Incluso a veces pareciera que entre la carrera académica y el trabajo intelectual se interponen gravísimos obstáculos. El intelectual, en la medida que entra en un diálogo informado y crítico con su sociedad, requiere de una libertad que no siempre las universidades le reconocen. Alberto Hurtado realizó un trabajo intelectual principalmente fuera de la universidad.

Hurtado intentó lo que, según algunos, han pretendido los intelectuales desde antiguo. En un libro reciente, Jeffrey C. Goldfarb fácilmente ubicaría a Hurtado entre los hombres que han tenido por interlocutor primero a su propia sociedad (18). En su caso no es una, sino varias las ideas que lo mueven. Ciertamente "lo social" constituye su preocupación característica, pero su inquietud abarca todos los dominios de la vida humana. La distinción de Golfarb entre las dos funciones típicas de los intelectuales es claramente aplicable a Hurtado: la función "subversiva" y la función "cívica" (19). Como tantos pensadores, Alberto Hurtado fue incómodo a su época. Su crítica tuvo por objeto una sociedad y un catolicismo que no cuadraban en su idea de cristianismo. Pero en él se advierte, sobre todo, un pensamiento constructivo, la reflexión propia del pastor y del educador que colabora con otros en la misión formadora de su Iglesia (20).

Últimamente el P. Tony Mifsud, al presentar Moral Social, su obra póstuma, afirma sin sombra de duda: "este libro, por cierto no acabado, es la obra de un intelectual, es decir, de un hombre que, además de llevar adelante un enorme trabajo social, también encontró tiempo para pensar la acción social y articularla de manera coherente y sistemática" (21). Más adelante añade: "ciertamente, no fue un pensador

(17) Alvaro Lavín, El Padre Hurtado: Apóstol de Jesucristo, Santiago, 1977, p. 28.

(18) Jeffrey C. Goldfarb Los intelectuales en la sociedad democrática, Cambridge University Press, Madrid, 2000.

(19) J. Goldfarb, o.c., pp. 60 ss.

(20) A propósito de la universidad, afirma: "sentido del escándalo siempre vivo: sus ojos abiertos al mal, no para deshacerse en crítica estéril, sino para remediar y construir. La única razón de ser crítico es ser constructivo, como la única razón para echar abajo una casa es edificar otra en su lugar" (S22 y 24: "Lo que ha de despertar la universidad en sus alumnos").

(21) Informe Ethos $\mathrm{N}^{\circ}$ 40: Alberto Hurtado S.J. ¿Una voz en el desierto?, Universidad Alberto Hurtado, 2, 14, 2005. 
especulativo, en el sentido de pensar lo pensado, sino más bien un intelectual práctico, ya que lo que le motivaba era el cambio social, es decir, pensar la realidad social para cambiarla. La realidad era el punto de partida de su preocupación intelectual y su pensamiento se dirige a su transformación" (22).

Alberto Hurtado fue un intelectual con una poderosa inclinación a la acción apostólica directa y fue un hombre de acción con una inquietud y una preparación intelectual notable. Ambas cosas. Pero esta constatación no basta. Es necesario saber cómo ello es posible.

\section{c) Un "contemplativo en la acción"}

Alberto Hurtado actuó como un intelectual y como un hombre de acción. Pasó del trabajo intelectual a la acción y de esta a aquel. Por ello podrá preguntarse "qué fue más", y concluir, por ejemplo, que fue sobre todo un hombre de acción porque dedicó más tiempo al apostolado directo. A caballo de este planteamiento podrá también pensarse que haya que restringir su calidad intelectual a la preparación que le sirvió para sustentar su actividad apostólica, pero que "lo intelectual" no haya sido una inquietud y una ocupación suya permanente.

La oposición entre estos dos aspectos de Hurtado, sin embargo, arriesga esconder, tras una imagen exterior y superficial, la compenetración interior y profunda entre ellos que él, como "contemplativo en la acción", realiza. La integración que el jesuita hace entre ambas actividades impide distinguirlas sin mediarlas estrechamente. El hombre en este caso es uno solo. Hurtado llega a identificar la contemplación cristiana con el engagement, el compromiso "a fondo", distanciándose de aquella "idea pagana" que conduce a divorciar la sabiduría del trabajo (23). Es cierto que unas veces él realiza una actividad intelectual y otras una acción transformadora de la realidad, pero llevadas las cosas a su origen, hay que retener que cuando Hurtado se desempeña como hombre de acción lo hace de un modo intelectualmente cualificado; y, viceversa, cuando incursiona en el ámbito intelectual lo hace movido por un afán de cambiar el mundo.

El origen de la peculiar integración en Hurtado de teoría y praxis, se encuentra en la espiritualidad ignaciana. Por esta razón es preciso evitar un concepto de pietas que no es la suya. Nada puede alejarnos más del concepto mismo de santidad de Alberto Hurtado que adjudicar esta a su oración formal, a su devoción a María y a los santos, a su práctica de los sacramentos, a su buena conducta o a sus "milagros". No obstante ser verdaderas en él estas virtudes, atribuir a cualquiera de ellas su santidad nos despista de su auténtica piedad. En Hurtado la "mística", el hecho de ser unido con Dios por Dios mismo, la visión de Dios en el pobre y del pobre en Dios, la escucha de Dios a través de la cual comprende su misión en el mundo y redescubre su vocación, la contemplatio por decirlo con una sola palabra, troquela su intelectualidad y le urge una praxis apostólica característica (24). Su pietas en

(22) Ibídem, 2, 17.

(23) Cf. S17 y 05: "Apuntes formación juventud obrera".

(24) En la discordia que se suscitó con el P. Raúl Silva Silva, director espiritual del Seminario de Santiago, quien lamentaba que Hurtado hubiera inquietado a los seminaristas con una predicación de la acción 
vez de desconectarlo de su intelecto, estimula su actividad intelectual y esta ilumina permanentemente su praxis; y, al revés, Hurtado es consciente de que la pietas se nutre a su vez del aprendizaje que proviene de la práctica y que obliga a modificar el conocimiento. La pietas no encierra a Hurtado en su alma. Al contrario, lo saca fuera, lo abre a la totalidad de la realidad, le obliga a aquella receptividad que hace ulteriormente incapsulable a Dios a través de un intelecto y una acción que deben, sin embargo, esforzarse por comprenderlo por ser él, y solo él, el autor de un mundo cristiano. Su eruditio es una dimensión inextirpable de su pietas apostólica. En Hurtado una eruditio que se sirve a priori de todas las posibilidades científicas y teológicas al alcance, sostiene una pietas capaz de registrar los "signos del tiempo" e impulsa la acción que verifica la actuación trascendente de Dios en la historia.

La clasificación de las actividades de Hurtado para determinar cuál ha sido su personalidad, decir por ejemplo que dedicó el máximo de energía a la fundación del Hogar de Cristo y en consecuencia que fue un santo de la beneficencia social, no un intelectual, mueve definitivamente a engaño. Hacer competir en Hurtado su inclinación a la acción en contra de su inquietud intelectual desvirtúa su genialidad espiritual. Que la contribución de Hurtado a las ideas haya sido pobre o rica, que sea cierto o falso que haya sido un difusor del pensamiento de otros, es en realidad un asunto secundario. Lo que valoramos de él es la integración espiritual de dos dimensiones heterogéneas, su actividad práctica y su reflexión intelectual, que no se restan una a la otra, porque progresan una y otra en la misma medida que compenetradas se potencian recíprocamente. Nada más falso se ha dicho de Hurtado que su apostolado social tiñó su santidad de activismo y de socialismo; que su santidad ha consistido en su oración y su relación íntima con Dios.

La separación indicada ha servido para empañar la original "vocación social" del P. Hurtado. Estos días que celebramos su canonización, se hace necesario repetir que su pietas es otra distinta de aquella que hace competir "lo espiritual" en contra de "lo social". Alberto Hurtado es un "místico social". La separación de su santidad respecto de su preocupación social tiene visos de ortodoxia ante el tribunal de la antigua mística griega, pero de heterodoxia en la tradición del camino cristiano. En cuanto "místico social" Hurtado es un santo hondamente cristiano. Su solicitud por aliviar a los pobres y desmontar una sociedad que generaba miseria, no perjudica su testimonio sino que lo valida como cristiano. Al mismo Hurtado la posibilidad de un cristianismo que aleje del mundo le ha parecido inaceptable (25).

que en cierto sentido minaba la formación que él daba en el Seminario y que sobreestimaba la oración, el jesuita aclara al P. Silva que nunca ha querido incitar a los seminaristas "a la acción inmediata", pues según él, "así como un seminarista se forma en la oración y en el sacrificio (según el decir de Silva), ha de formarse también en el estudio del mundo en el cual ha de actuar..." (Jaime Castellón (ed.) Cartas e informes del Padre Alberto Hurtado S.J., Ediciones Universidad Católica de Chile, p. 110). El intercambio de cartas debió allanar una incomprensión cuyo origen no ha sido un mero malentendido. En la discusión que los seminaristas mantuvieron con Hurtado, y que la misma carta al P. Silva refleja, se advierte una diferencia real en el modo de concebir la articulación entre contemplación y acción, aun cuando no hay que exagerar esta diversidad, pues de lo contrario se llegaría al absurdo de pensar que era ajena a la formación del Seminario una preocupación por formar a los seminaristas en el conocimiento de la realidad. En todo caso, mientras el P. Silva afirma que "la oración debe ser diez veces más que la acción" (Alvaro Lavín, El Padre Hurtado S.J. Amigo y apóstol de los jóvenes, Imprenta San José, Santiago, 1978, p. 121), Hurtado reconoce que él tiene "por vocación una vida más consagrada a la acción" (J. Castellón, o.c., p. 112).

(25) S19 y 13: "Medios divinos y medios humanos". 
El carácter de "místico social" especifica en el caso de Alberto Hurtado aquella característica jesuítica suya de ser "contemplativo en la acción". En Hurtado confluyen la espiritualidad ignaciana y la valoración moderna de la praxis para cambiar la sociedad, para cambiar las estructuras, para cambiar la historia. La acción tiene en él la misma importancia que años después tendrá en la teología de la liberación latinoamericana (26). Como a esta teología, también a él lo acusarán de "pelagianismo". Hurtado conoce el tema. Es probable que haya equilibrado contemplación y acción mejor en la teoría que en los hechos. Sabe que el cristianismo no consiste tanto en conocer a Dios cuanto en hacer su voluntad. La expresión que mejor refleja la orientación práctica de su piedad, y que hoy circula como el leitmotiv de su vida espiritual, es la pregunta que formuló de tantas maneras distintas y que reza: "qué haría Cristo en mi lugar" (27). Esta acción social, que en la práctica admite tanto la caridad como la lucha por una sociedad más justa, supone e informa la actividad contemplativa.

La actividad contemplativa, a su vez, tiene dos momentos que, a falta de términos adecuados, podemos llamar: entendimiento interior y erudición a secas. Alberto Hurtado, en cuanto hijo de San Ignacio, vive abierto al Espíritu que le permite amar a Dios en todas las cosas y a estas en Dios (Constituciones, 288), aptitud esta que ha desarrollado a partir de la contemplación en las Sagradas Escrituras de la actuación histórica en Jesucristo. Su mirada es amplia y contemplativa en sentido estricto. Dios no se priva de nada con tal de comunicarse con su criatura. Si en los sacramentos tenemos certeza de la presencia y actuación divina, la voluntad de Dios puede ser captada por la mirada contemplativa en toda la creación (28). En este plano es Dios quien se muestra interiormente y por propia iniciativa. Que Alberto Hurtado diga "el pobre es Cristo" (29) será siempre una gracia concedida al hombre que durante los Ejercicios Espirituales pidió "conocimiento interno del Señor, que por mí se ha hecho hombre, para que más le ame y le siga" (30).

Por otra parte se da en él una erudición o una teoría aprendida de otros. A saber, los conocimientos que Alberto Hurtado adquirió como el común de los estudiantes. Los suyos se obtuvieron con largos años de formación: Derecho, Humanidades, Filosofía, Teología y Pedagogía. Incursionó en la psicología de la juventud. Es muy probable que hubiera gustado aprender más de Ciencias Sociales y Económicas. A estas disciplinas hay que añadir un sinfín de otras lecturas que lo hicieron un hombre culto. Adquirió un conocimiento cabal de la tradición y de la Doctrina Social de la Iglesia. En todas estas materias la contemplación ha tenido lugar a través de un aprendizaje de otro orden, pero igualmente ha sido teoría que guía la acción. Estos conocimientos serían inútiles para una transformación cristiana de la realidad, sin el conocimiento interior de la acción del Espíritu en las personas y en

(26) Dirá: "El verdadero cristiano, incluso el legítimo contemplativo para semejar a su padre se esfuerza también por ser una fuente de bienes lo más abundante posible. Quiere colaborar con la mayor plenitud a la acción de Dios en él. Nunca cree que hace bastante. Nunca disminuye su esfuerzo. Nunca piensa que su misión está terminada" (S19 y 13).

(27) S45 y $10 ; \mathrm{S} 46$ y $8, \mathrm{~S} 42$ y $01 \mathrm{~m}$.

(28) $\mathrm{S} 19$ y 13

(29) S03 y 01b, S10 y 08; S10 y 18.

(30) Ejercicios Espirituales, No 104. 
la historia. Pero la contemplatio interior sin la eruditio, tampoco podría hacer de este un mundo más justo. Alberto Hurtado que lo sabe muy bien, nos precave en contra de la ignorancia, particularmente la del clero. Una pietas sin eruditio significaría para Hurtado desentenderse de la suerte de los pobres.

\section{UN PUENTE ENTRE LA IGLESIA Y SU ÉPOCA}

Alberto Hurtado intentó un diálogo informado con la sociedad y, en particular, con la sociedad católica de su época. Pero, además, tuvo un concepto de sociedad y de las relaciones de la Iglesia con esta sociedad, en una época en crisis, en tiempos en que la llamada "cristiandad" experimentaba en Chile nuestras fracturas.

\section{a) Divorcio entre fe y cultura}

Pablo VI ha señalado que "la ruptura entre Evangelio y cultura es sin duda alguna el drama de nuestro tiempo..." (Evangeli Nuntiandi, 20). Treinta años después confirmamos la lucidez del papa para reconocer un cambio de época (31). Hace ya siglos que la modernidad cuestiona la fe y aparta a sus fieles de la Iglesia. ¿Qué grado de conciencia ha tenido Hurtado de este divorcio? ¿En qué medida él mismo ha podido darse cuenta del fin de la cristiandad? Es este un asunto que merece una investigación cuyos resultados serán muy importantes a quienes interese comprender no solo las dificultades actuales de los pastores para relacionarse con la gente de su tiempo, sino también para asomarse a la aguda crisis del sacerdote recién comenzado el siglo XXI. En esta sección nos conformaremos con avanzar a tientas, esbozando una respuesta especialmente a esta última cuestión.

Suponemos que en la mediación de pietas y eruditio, se anticipa existencial y reflexivamente en Hurtado el divorcio entre fe y cultura señalado. Hay elementos para afirmar que en alguna medida el santo jesuita es víctima de esta fractura, pero también que protagoniza una gesta heroica por tirar un puente entre la Iglesia y sus contemporáneos. Se da en Hurtado una turbulencia que amén de psicológica, se activa por la urgencia de evangelizar un mundo progresivamente menos cristiano y menos católico. A veces la angustia del santo roza el pesimismo. Alguien podría creer que para Alberto Hurtado "todo tiempo pasado fue mejor". La fatalidad ante los nuevos acontecimientos caló a muchos católicos durante el siglo XX. Con Hurtado es posible equivocarse. En sus escritos se puede rastrear al sacerdote agitado por una lucha interior entre lo viejo y lo nuevo, entre lo que hay que anunciar y lo que hay que denunciar, entre lo que es necesario mantener y lo que es preciso crear. El apasionamiento, la impaciencia de Hurtado conjuga un desgarro epocal. Sus ocupaciones son múltiples, cualquier tema le interesa, todos sus escritos tienen algo de provisorio. Se le acusa de descuidado. Se excusa. Pero continúa igual. Hurtado cae en la cuenta de lo que otros

(31) Los obispos chilenos hablan de "un cambio de época de grandes proporciones" (Orientaciones Pastorales 2001-2005, N $\mathrm{N}^{\circ}$ 3) y de "un tránsito cultural de proporciones" (En camino hacia el Bicentenario de la Independencia Nacional, $\mathrm{N}^{\circ}$ 6). 
sacerdotes no ven, se queja a Pío XII de los obispos. Incluso algunos superiores jesuitas reclaman que divide la provincia; los formadores le restringen el trato con los escolares; el visitador Crivelli cree que carece del espíritu propio de la Compañía. Aunque las críticas hieren su sensibilidad, Hurtado no cede. Sigue adelante. No le da lo mismo que tantos se alejen de la Iglesia y menos los pobres.

Uno o varios estudios atentos debieran investigar cómo en Hurtado se recicla la espiritualidad ignaciana, en ruptura con la vida monástica (32); cómo en él la moral sexual y familiar tradicional resiste, aunque relativizada por la miseria del pueblo (33); y cómo en su pensamiento la cristiandad se agrieta y se supera. En el cambio de época en fermentación, es imposible que Hurtado no pertenezca a dos mundos, el antiguo y el nuevo. ¿Quién pudiera jactarse de permanecer exclusivamente en alguna de estas orillas? Sería absurdo siquiera imaginarlo. Lo que hace a Hurtado un santo cristiano y católico es procurar la integración, siempre ardua, de todas las dimensiones de la vida a partir de la experiencia de fe. Busca un cristianismo integral. Él mismo está en camino. Lo que lo caracteriza es el esfuerzo de una síntesis progresiva. Y en particular la integración social que intenta. Hurtado se sabe pontifex, "puente" de reconciliación social entre la Iglesia y su época (34). No podemos encontrar su aporte en otras cosas. Nos distraeríamos de la acción principal del Espíritu a través suyo. Como bien comprendieron Lavín y Larraín, su santidad se reconoce en su "vocación social" (35).

(32) Desde tiempos de San Ignacio la Compañía de Jesús ha experimentado presiones, a veces exitosas, para encauzársela en la vida monástica. Ignacio resistió al máximo esta imposición. Nadal insistió en el carácter no monacal de la Compañía. Se acusa a San Francisco de Borja, en cambio, de haber conventualizado a la Orden. La restitución de la Compañía en el siglo XIX, traumada después de la supresión, se hizo en términos tradicionalistas. Pues bien, Alberto Hurtado representa en Chile un retorno a las fuentes. Varias de las críticas apuntan a una inobservancia de un tipo de vida comunitaria que no parece haber sido la de los primeros compañeros. Hurtado entra y sale de la residencia de Alonso Ovalle 1480 a cualquier hora. Dispone de una camioneta. Tiene teléfono. No observa horarios de queda. Pero, lo más notable, es que Hurtado saca a los jesuitas chilenos del claustro. Al crear nuevas obras distintas a los colegios tradicionales, al reclamar de los jesuitas una conexión con el mundo externo más amplio, Hurtado se convierte en otro fundador de la Compañía para los jesuitas chilenos. El nuevo santo recupera para la Compañía de Jesús la compenetración de lo sagrado y de lo profano, típica del cristianismo, en el plano de la espiritualidad. Para él Cristo está en la calle y en la historia, luego allí hay que encontrarle. Es esta versión "moderna" de la vida religiosa la que impedirá a otros comprender o interpretar correctamente la santidad de Hurtado.

En honor a la justicia hay que recordar otros nombres que cambiaron la provincia chilena de la Compañía de Jesús: Krebs, Alvarado, Marambio y Weigel.

(33) En este plano Hurtado se muestra intransigente en la doctrina y profético en su aplicación. No parece que en esta materia haya en él mayor novedad teórica. No es fácil descubrir aquí un esfuerzo por hacer avanzar la doctrina. Repite lo de los demás. Pero al momento de la aplicación de la doctrina, nuevamente es su visión social de la realidad la que le hace decir cosas que debieron sonar muy audaces: “¿Podrá haber moralidad? ¿Qué no habrán visto esos niños habituados a esa comunidad absoluta desde tan temprano? ¿Qué moral puede haber en esa amalgama de personas extrañas que pasan la mayor parte del día juntos, estimulados a veces por el alcohol? Todas las más bajas y repugnantes miserias que pueden describirse son realidad, realidad viviente en nuestro mundo obrero. ¿Hasta dónde hay culpa? O mejor, ¿de quién es la culpa de esta horrible situación...?” (A. Hurtado Humanismo Social, Editorial Salesiana, Santiago, 1984, p. 51).

(34) Hurtado entiende que lo suyo es "tender un puente entre la Iglesia y los hombres", pues "todo sacerdote debe ser pontifex" (S40 y 11).

(35) Dice de él Lavín: “Todos los que estuvieron más cerca de él, lo acompañaron y mejor lo conocieron en su breve, pero intenso apostolado, están de acuerdo en afirmar que esta vocación especial 
De aquí que el discernimiento de la articulación entre la pietas y la eruditio apostólicas de Hurtado se centra en la cuestión de la crisis de la cristiandad (36). El pobre en el que el P. Hurtado ve a Cristo, es el pobre de una sociedad católica en crisis.

\section{b) Señales de una crisis}

Por "cristiandad" entendemos aquí esa unidad política y religiosa que comenzó con la adopción del cristianismo como religión del Estado por los años de los emperadores romanos Constantino y Teodosio, y que maduró en la Edad Media europea mediante el servicio recíproco de la política a la fe y de esta a aquella. En otras palabras, la cristiandad ha sido aquella civilización que, inspirada en Cristo o usando meramente su nombre, fue organizada por el poder político y por el poder clerical, padeciendo a sus tiempos los efectos del cesaropapismo o del papocesarismo. En cualquier caso la cristiandad ha sido expresión de la síntesis cultural que ha hecho posible a Occidente. Con la irrupción de la modernidad, esta síntesis se desmoronó en los países que la elaboraron. En el "viejo mundo", definido ahora como "postcristiano", hay católicos que se alegran de su término (37). Entre nosotros, en Latinoamérica, la disolución de la cristiandad aún está en curso. Tanto la Iglesia como la sociedad sufren las consecuencias de su ocaso.

Para el P. Hurtado la crisis de la relación fe y cultura, expresada en el plano de la relación de la fe y la política, y de la Iglesia y del Estado, es una realidad que sufre en carne propia. Distinguimos en ella tres aspectos: la crisis de su época, la crisis de su Iglesia y la crisis de la relación propiamente tal entre su época y su Iglesia.

fue la social" (A. Lavín, La vocación social del Padre Alberto Hurtado SJ, Santiago, 1979, p. 9). Mons. Larraín en la homilía de su funeral sostiene: "Y he dejado para el último lo que caracteriza su vida: su honda y trascendente misión social" (Mensaje, Ed. especial, agosto 1992 (corregida y aumentada), p. 133.

(36) Las palabras siguientes de Pedro Morandé ubican la preocupación sindical del P. Hurtado en sus coordenadas históricas principales $\mathrm{y}$, de paso, indican el cambio de paradigma en la relación Iglesia-Estado sobre la cual el jesuita cabalga. "Le preocupaba que una vez zanjada la cuestión religiosa mediante la separación de la Iglesia y del Estado consagrada en la Constitución del 1925 y la aceptación consiguiente de un cierto grado de secularización del espacio público, la conciencia de los católicos no percibía con claridad que el nuevo y más importante desafío al cristianismo venía del escenario social, puesto que a través de él se hacía manifiesta la gran influencia del marxismo y, simultáneamente, la ausencia de cristianos entre los obreros y los nuevos grupos urbanos. La dirigencia católica se había quedado anclada, en su percepción, en el horizonte rural, manteniendo en el campo una dominación casi 'feudal', como la denomina. Pero tanto o más grave que esta forma de gobierno de los asuntos agrícolas era para él la insensibilidad e indiferencia de los cristianos frente a la movilización social en los nacientes núcleos urbanos que acogían a los trabajadores inmigrantes por la reducción del trabajo minero, particularmente, de las salitreras. A diferencia de los agrícolas, estos trabajadores habían sido sindicalizados, sabían organizarse, tenían mayor experiencia en la lucha social y su orientación era más bien anarquista o marxista y, en todo caso, no cristiana" (citado por W. Thayer Ni político, ni comunista. Sacerdote, sabio y santo, Ediciones Olmué, 2004, p. 176).

(37) Cf. Michel Albert, Jean Boissonnat y Michel Cambdessus, Nuestra fe en este siglo, Desafío, S.A., Santiago, 2004, p. 33. 
a) El hecho de que la cultura deje de ser cristiana, constituye para Alberto Hurtado el principio de la decadencia que advierte (38). No obstante apreciar el arte en sus diversas expresiones, por tomar un ejemplo, tiene la impresión de que la pérdida de la fe en el arte contemporáneo ha privado a este de la belleza. El tema requiere una investigación más a fondo, porque en virtud de la teología del Logos que Alberto Hurtado conoce, valora la creatividad humana independientemente de su origen cristiano explícito. Pero sin duda lamenta la emancipación del arte de la fe. Sus quejas contra el biógrafo son reiteradas.

Lo que más le llama la atención, sin embargo, es la miseria, la injusticia social que la provoca y la emergencia de los conflictos sociales planetarios que esta injusticia a su vez incoa. La masiva pobreza es la señal más clara de una crisis mundial. No hay duda que Hurtado es moderno al menos en la concepción de esta pobreza. Para el hombre antiguo esta ha podido ser parte de un mundo dado, que él podía mitigar con su caridad, pero no imputarse a su responsabilidad. El hombre moderno, en cambio, tiene conciencia de que el orden social es un orden histórico, que es obra de la libertad y que, en consecuencia, se puede cambiar. Alberto Hurtado, en este sentido, no solo reclama caridad y justicia para los pobres, sino que exige sobre todo un cambio de las estructuras sociales. El orden social, especialmente la ordenación económica de la realidad, le parece gravemente desordenada, constituye un auténtico pecado, no es cristiana, y urge por tanto a su completa reforma.

b) En su obra ¿Es Chile un país católico?, Hurtado pareció a algunos de sus contemporáneos tremendamente pesimista (39). En este libro analiza extensamente la crisis del catolicismo nacional. Su crítica es aguda. Pone al descubierto la insignificancia del catolicismo de un país que ignora gravemente los datos principales de la fe. Se diría de él que se comporta como uno de esos "profetas de calamidades" denunciados por Juan XXIII, aquellos católicos laicos o sacerdotes siempre dispuestos a condenar el presente. Pero los que lo objetan son los viejos católicos. Son los conservadores los que mitifican el rol de la Iglesia en el pasado y no toleran que se cuestione el catolicismo actual. Dice de él L.R.Z. (40) en uno de sus cinco artículos publicados en el Diario Ilustrado: "El bello y sólido edificio levantado por la Iglesia y los católicos chilenos, podrá tener sus grietas, pero no está en ruinas, como el autor de libro en cuestión lo presenta. Su autor quiere restaurarlo, pero cae en el

(38) Cf., S57 y 17: "Problemas espirituales contemporáneos".

(39) Cf. Pedro Espinosa, S.J. “¿Es Chile un país católico?” Hacia un nuevo catolicismo chileno, (Manuscrito $\mathrm{N}^{\circ} 4.2$ )

(40) Mons. Miguel Ángel Alvear Fritz, secretario de Mons. Alfredo Silva Santiago en la diócesis de Concepción. Otro objetor del libro fue Mons. Alfredo Cifuentes Gómez, obispo de Antofagasta. Mons. Cifuentes, entre otras observaciones, representa a Hurtado señales de vitalidad del catolicismo chileno, enrostrándole su propia obra: Me veo tentado, para demostrar la generosidad católica chilena y la prosperidad que ella proporciona a las Congregaciones Religiosas, a citar por lo menos el caso de una de ellas que ha podido hacer un soberbio Noviciado, Casa de Ejercicios y Parroquia, por valor de más de cuatro millones de pesos reunidos con incansable celo por uno de sus religiosos que S.R. y yo conocemos muy bien... Y esa Orden que contaba sus novicios chilenos hace 25 años con los dedos de una sola mano, hoy no le bastarían tal vez cinco manos para contarlos... Es para preguntarse ¿Es Chile un país católico?” (Archivo S.J. CHL. Carta de Mons. Alfredo Cifuentes Gómez al P. Hurtado. Santiago, 14 de abril de 1942). 
peligro de demoler demasiado con la picota del pesimismo" (41). En palabras de Pedro Espinosa, S.J.: "la visión de L.R.Z. enfatizaba el orden y paz de 'antes', cuando los católicos gobernaban los destinos del país. La de Hurtado, asumía la preocupación 'del presente y del futuro' por los problemas sociales. Aquel, ante los desafíos de los tiempos, buscaba la solidez de la tradición y el retorno a los valores perdurables y ciertos. Este, sin desligarse de la mejor tradición, buscaba nuevas andaduras para los desafíos del tiempo" (42). Así lo entendieron los progresistas de la época, que celebraron la publicación del libro. Por esto lo defendieron Gustave Weigel, decano de la Facultad de Teología, y Monseñor Larraín, su amigo, aun admitiendo algunos defectos de la publicación.

La crítica de Hurtado es ilustrada. La administración de los sacramentos sin una adecuada catequesis que eduque al pueblo en la religión del amor a los hermanos, habría sido difícil de implementar en un país con un alto grado de analfabetismo. Con todo, Hurtado carga las culpas a la escasez de clero, pero no solo a ella. En varias ocasiones desliza una crítica a su mediocridad. Tiene la impresión de que es un clero "bueno", pero acomodado e ignaro de la honda crisis de la Iglesia. En privado Hurtado se queja a Pío XII en contra de obispos que no parecen enterarse "de la inmensa tragedia que nos va a coger desprevenidos". Lo más grave, continúa en su memorial, "es la pérdida de confianza en la Jerarquía de parte de muchos. Le reprochan falta de comprensión del momento social y no se cree en su trabajo y dedicación al proletariado" (43). Y, por cierto, su crítica más dura la dirige contra los católicos ricos y contra la versión burguesa del cristianismo. "Paganismo con un manto social de cristianismo" (44), dirá.

c) Llama la atención, por último, la lucidez de Alberto Hurtado acerca de la ruptura entre la Iglesia y el mundo de su tiempo. Afirma: "Están desapareciendo las seguridades de un orden llamado cristiano. El vacío entre la Iglesia y el mundo se ensancha cada vez más, como lo comprueba el sacerdote que no se encierra en la sacristía y con sinceridad abre sus ojos a la vida. Él nota la tremenda extrañeza que causa su roce con su tiempo y sus contemporáneos..." (45). Estas palabras, oídas a más de medio siglo de distancia, indican proféticamente que el divorcio mencionado habría de agudizarse.

(41) “Es Chile un país católico? Analizando un libro”. El Diario Ilustrado, 10 junio, 1942.

(42) O.c., $\mathrm{N}^{\mathrm{o}} 4.2 .5$.

(43) J. Castellón, Cartas, o.c., pp. 198-203.

(44) “¿Cuánta alianza ahora entre cristianismo y mundo! Una misa tardía, oída de cualquier manera, es lo único que rompe el ambiente pagano de las 24 horas del día, de los siete días de la semana, de los 365 días que tiene el año... ¿Es eso cristianismo? Sucesión ininterrumpida de fiestas en la ciudad, y de diversiones mundanas en la playa, casino, ruleta, boites, bailes, programas radiales, excesos alcohólicos de los hombres y... por desgracia ahora hasta de las mujeres. Esto no significa que el cristianismo prohíba las diversiones sanas, los honestos entretenimientos; pero una vida con programa de diversión ininterrumpida, ciertamente no responde a los ideales de Cristo. No decimos que se cometa pecado mortal en cada una de esas acciones, tal vez en ninguna de ellas separadamente, pero sí afirmamos que esa vida no corresponde a lo que Cristo vino a traer a este mundo; y que en el fondo todo eso es paganismo con un manto social de cristianismo y constituye una de las causas más profundas de la apostasía de las masas" (A. Hurtado Humanismo Social, o.c., p. 65).

(45) S40 y 11: "La formación del sacerdote". 
Hurtado avizora que los grandes perdedores de esta situación serán la Iglesia y el mundo. La secularización de la clase obrera, su pérdida de la fe y su alejamiento de la Iglesia, es lo que más le duele. Pero también lamenta la suerte de su Iglesia. La "gran tragedia del catolicismo chileno", cree él, estriba en la disociación entre la doctrina y la realidad. Diagnostica una brecha creciente. Como sacerdote se siente llamado a estrechar las distancias, a reconciliar a los enemigos, a allanar el camino a una integración cristiana de todos los aspectos de la vida (46).

Esta visión crítica de Alberto Hurtado, sin embargo, es expresión de su fe. Si no fuera por su fe en el Dios que guía interiormente la historia, el no vería lo que critica. Hurtado es inconformista porque está convencido del reino de Dios inaugurado por Jesucristo. El reino es ya una realidad que es necesario que se despliegue en todas las direcciones. Al padre Hurtado lo mueve la esperanza. Si advierte el drama de los que él llama "nuestros atormentados tiempos" (47), es porque conoce la realidad de un mundo mejor que debiera verificarse ya ahora en la tierra. Definitivamente no es ningún catastrofista. No es un reaccionario. No lo moviliza el miedo a los cambios ni el pánico a lo que pueda suceder, sino el amor capaz de inclinar la historia en la dirección del reino. Su fe en Dios le hace "ver más". La primera página del primer número de la revista Mensaje es prueba de su mirada creyente de la realidad: "Nuestros contemporáneos dan la triste impresión de peregrinos que cruzan un desierto, muriendo de sed, y sin saberlo están pasando por sobre ríos subterráneos: con solo cavar un poco, tendrían fuentes de aguas vivas que saltan hasta la vida eterna". El desaliento no es posible. La mera condena de una cultura en decadencia probaría exactamente una falta de fe (48).

Aún antes del Concilio Vaticano II que popularizará la teología de los "signos de los tiempos", el padre Hurtado practica esta teología, escrutando en los hechos históricos la acción de un Dios que no cesa de crear (49). La acción de Dios en los acontecimientos, razón de la esperanza del cristianismo, está al principio y al final de la pasión espiritual e intelectual de Alberto Hurtado.

\section{c) Superación de la cristiandad}

Hay razones para pensar que Hurtado ha quedado a medio camino en la superación de la cristiandad. Su "mística social" funcional a un "orden social cristiano", pudiera legitimar a la pasada la restauración del ancien régime en el que la Iglesia

(46) A los universitarios les hace un llamado de atención: "Producir la síntesis entre nuestras doctrinas y nuestras realidades, entre nuestras aspiraciones y nuestras posibilidades, entre un orden teórico y la capacidad de realizaciones llevado al máximo en un momento dado: he aquí una inquietud que la Universidad debe despertar en sus alumnos y que no puede darse por contenta mientras no la haya realizado" (S08 y 10: "Misión del universitario").

(47) S08 y 03.

(48) En un texto que otorga una importancia desmesurada al sacerdote, Hurtado muestra empero su esperanza frente al futuro y ante la posibilidad de integración de fe y cultura: "Se ve que la cultura de Occidente está en decadencia (como hay decadencia moral, literaria, filosófica...) y será el sacerdote el que ahora ha de salvar esta nueva encrucijada de la historia, poniendo a salvo los valores eternos en peligro, e incorporándolos en síntesis armónica con los nuevos conocimientos científicos" ( $\mathrm{S} 40$ y 11).

(49) En la misma revista Mensaje inauguró una sección titulada "Signos del tiempo". 
católica y la sociedad constituyeran una unidad. ¿Cuánto tiene de nostálgica su crítica a la civilización moderna? Esta, afirma, "olvidada del hombre, no se preocupa sino del lucro, no de las necesidades humanas sino de vender aunque sea creando artificialmente necesidades" (50).

La vocación social de Hurtado lo lleva a obtener limosnas para los pobres y a luchar para que Chile sea un país cristiano, mediante una economía y una legislación que favorezcan la eliminación de la miseria del pueblo. Pero ¿qué tipo de rol otorga a la Iglesia en la consecución del "orden social cristiano"? Son numerosas las pruebas que indican que Hurtado no concibe una sociedad cristiana sin que en ella la Iglesia, y el sacerdote en particular, jueguen un papel clave. Se podría decir que es incluso desmesurada la importancia que reconoce al sacerdote (51), lo que en un país católico no puede sino traducirse en un influjo decisivo de este en el ámbito público. De los obispos espera alguna actuación política de mayor altura, pero admite también que en ciertos casos puedan dirigir inmediatamente la acción política de los laicos.

Otros datos reforzarían la posibilidad de que Hurtado fuera un católico restauracionista. Hurtado no cortó absolutamente los lazos con el Partido Conservador, en el cual participó activamente en su juventud. Aun habiendo roto con este, al defender ante el Papa a los jóvenes de la Falange Nacional, ha podido quizás reciclar el clericalismo a través de un nuevo partido que canalizara mejor la doctrina pontificia para la configuración de una sociedad más justa (52). Alberto Hurtado, además, no fue indiferente a la penetración protestante en Chile. Exigió para su gente respeto, tuvo palabras incluso admirativas, pero no le dio lo mismo que Chile fuera o no un país católico (53). Estos datos merecen un análisis más fino. Este probablemente

(50) Con estas palabras hace suyo el pensamiento del P. Lebret (S20 y 07).

(51) El más grave de los problemas es, según el P. Hurtado, la falta de sacerdotes, porque del sacerdote parece depender todo en orden natural y en el sobrenatural: "La misión del sacerdote engloba la del maestro, confidente, amigo, abogado, defensor de los débiles, apoyo de los pobres. Al sacerdote se le pide todo: la formación en la piedad, la solución de los problemas más difíciles de la vida, organizar las obras sociales y, sobre todo, comunicar a las almas, mediante los sacramentos, la gracia que ennoblece y eleva al hombre al plano divino. Sin sacerdotes, no hay sacramentos; sin sacramentos, no hay gracia, no hay divinización del hombre, no hay cielo. Por eso se ha dicho con razón que nada hay tan necesario como la Iglesia, y en la Iglesia nada tan necesario como los sacerdotes” (A. Hurtado, ¿Es Chile un país católico? Dolmen, Santiago, 1994, p. 226).

(52) J. Castellón, Cartas, o.c., pp. 201-202. Según William Thayer, confidente del P. Hurtado en este punto, Pío XII reaccionó indignado por la colaboración de la Falange con los comunistas. Nunca se supo que Hurtado hubiera contado a otros el episodio. Habría sido muy delicado hacerlo (cf. W. Thayer, o.c., p. 112).

(53) En su libro ¿Es Chile un país católico?, el P. Hurtado tiene textos que pueden ser interpretados fanáticamente en contra de los protestantes. Dice, por ejemplo: "Los prejuicios inveterados que ha formado el ambiente nacional durante siglos hacen que aún estos protestantes no adhieran al catolicismo, pero sus movimientos tienen un fondo marcadamente catolizante. Esto no quita, sin embargo, que sean un peligro para los católicos, ya que la verdad no consiste en una aproximación, sino en lo indivisible. Y en el error está el que afirma que dos y dos son cinco, como también el que afirma que son ochenta, aunque el primero esté más cerca de la verdad que el segundo. La verdad es una, indivisible y, por consiguiente, intolerante. No se puede pactar con la verdad: hacerlo sería desgarrar la túnica inconsútil del Maestro. Y el protestantismo es el error, ya que no es la verdad total. La verdad es una, la que prometió Jesús a la Iglesia fundada sobre Pedro, contra la cual no prevalecerán las puertas del infierno y a la cual prometió su asistencia hasta el fin de los siglos" (Cf. A. Hurtado, ¿Es Chile un país católico?, En Obras Completas, 
mostrará una oscilación en el P. Hurtado entre un modo clerical de relacionarse la Iglesia con el poder político y otro modo que pudiéramos llamar de inspiración cristiana de la sociedad. Pero, puesto Hurtado en su contexto histórico, él destaca clarísimamente entre sus pares porque espera que la sociedad cambie más a partir de una conversión de los católicos que a través de las prácticas tradicionales del clericalismo (54).

En realidad, el fenómeno más interesante de registrar en el P. Hurtado, el más novedoso, es la tendencia a la superación de la cristiandad. Los hechos hablan mejor que los textos. Alberto Hurtado fue sacado de la Acción Católica, entre otras razones, por una causa política (55). En virtud de la carta del Cardenal Pacelli al Episcopado chileno del año 1934, en el que se liberaba a los católicos de participar en la vida política a través de un único partido, el jesuita hizo caso omiso de las presiones por orientar a los jóvenes al Partido Conservador. En el otro extremo de la tensión, los obispos -muchos de los cuales veían con malos ojos la emergencia pública de líderes juveniles falangistas, debiendo los mismos obispos acatar por otra parte la indicación de Pacelli- le pedían abstencionismo político completo a los dirigentes del movimiento, cosa que a Hurtado le costaba aceptar, porque significaba privarse de gente capaz para dirigirlo. Hurtado defendió el pluralismo de la Acción Católica entre la exigencia episcopal de apoliticismo y el reclamo unipartidista de los conservadores en contra de la Falange Nacional, en una época que la unidad política de los católicos ya no se podía exigir, pero era todavía deseable para sectores conservadores muy influyentes de la Iglesia (56). Tal vez no haya sido el principio por sí mismo de la participación pluralista de los católicos en política lo que lo movió a

Dolmen, Santiago, 1994, p. 206-207). ¿Habría podido desdecirse el P. Hurtado de este tipo de textos con el pasar de los años? Que hubiera en él conciencia de su propia evolución intelectual, ciertamente la había (cf. Mensaje $\mathrm{N}^{\circ} 1$ [1951] p. 3). Estas líneas tan duras contra los protestantes contrastan con otras del mismo Hurtado sumamente laudatorias hacia ellos. En su obra Sindicalismo celebra el trabajo conjunto de católicos y protestantes en la acción sindical: "Católicos y protestantes están unidos en la C.I.S.C. en una común aceptación de las líneas fundamentales del orden social cristiano, pero guardan su plena independencia de criterio para apreciar tanto los problemas sindicales como los políticos que tienen atingencia a la vida sindical..." (S03 y 03b). En el pensamiento de Alberto Hurtado la praxis en favor de los pobres adquirirá prioridad sobre los asuntos teóricos que dividen a los hombres.

(54) Afirma: "Hemos de desear un orden social cristiano. Este supone el respeto a la Iglesia, a su misión de santificar, enseñar, de dirigir a sus fieles, y supone también algo tan importante como esto: que el espíritu del Evangelio penetre en las instituciones, y que las leyes se inspiren en la justicia social y sean animadas por la caridad. Un Estado es cristiano no solo cuando establece el nombre de Dios en sus juramentos, sino cuando el sentido del Evangelio domina su espíritu (Humanismo Social, o.c., p. 181).

(55) Según Gonzalo Vial, además del choque personal con Mons. Salinas, "la causa fundamental de que el Padre Hurtado abandonase la Asesoría Nacional, fue política" (Mensaje No 411 [1992] p. 299).

(56) Pedro Espinosa, S.J., sostiene: "En ambas controversias, la discusión de fondo era la divergencia entre los distintos modos de 'ser católico': la postura de Alberto Hurtado, de índole pluralista; la episcopal, que optó por una estricta neutralidad y la conservadora, acérrima partidaria del unipartidismo católico" (o.c., 4.2.4.). Según el mismo Espinosa, el Partido Conservador no podía tolerar que Hurtado admitiera el pluralismo en la Acción Católica. Católicos conservadores como don Carlos Aldunate "seguían pensando honradamente que no trabajar para el partido católico único, era trabajar a favor de los enemigos de la Iglesia" (ibídem, 4.2.4). 
zafarse de las expectativas de su antiguo partido, sino la búsqueda de otras vías políticas para la edificación de un "orden social cristiano" verdaderamente sensible a los pobres. En alguien que piensa a partir de las necesidades de la realidad como es su caso, lo que debemos captar es que este compromiso suyo con la causa de los pobres lo convirtió en un defensor acérrimo de la doctrina del Cardenal Pacelli, futuro Pío XII. Tal será la coherencia de Hurtado con este principio, que los jóvenes de la Falange, la actual Democracia Cristiana, tampoco podrán decir que tuvo por ellos una predilección especial (57). Una cosa fue la defensa privada que el P. Hurtado hizo de ellos ante el Papa; otra distinta sus sentimientos íntimos, de los que a este respecto sabemos poco; y distinto, además, un favoritismo público por el nuevo partido que nunca expresó.

Algo análogo sucederá con la Acción Sindical Chilena (ASICH). Alberto Hurtado la concibió como un movimiento parasindical, no como una alternativa al sindicalismo comunista y socialista (58). Hurtado combatió al marxismo. Los comunistas arrebataban a la Iglesia la clase obrera. Sin embargo, en vez de crear una institución sindical que hiciera de cuña al interior de la organización obrera, apoyó y defendió más bien la que hubo, aunque lo hiciera en virtud de principios teóricos diversos e incluso antagónicos. Hurtado valoró lo que la izquierda chilena hacía por la redención del proletariado, pero luchó para que los valores cristianos penetraran en la actividad sindical. Veía alarmado el grave peligro de la confrontación social creciente. Defendió la libertad sindical en contra de la hegemonía monopolizante marxista, pero se opuso a la Ley de Defensa de la Democracia que proscribía al Partido Comunista y empujaba a sus militantes al exilio. Le parecía que la "ley maldita" (según de decir de los que la padecieron) representaba una grave amenaza al movimiento sindical obrero. Poco tiempo después del fallecimiento del P. Hurtado murió también la ASICH. Los que lo sucedieron sustituyeron su visión parasindical por la de Tessier, el lider francés que promovía un sindicalismo católico paralelo (59). Los hechos más que los textos, dicen que Hurtado también en este plano deja atrás la cristiandad, pues entiende él que en una sociedad en la que no todos son católicos, los católicos deben colaborar con cualquiera, incluso si son comunistas, en favor de la sindicalización de los obreros.

Si alguna vez la cristiandad se asoció a una idea excluyente de la presencia de Dios y de la salvación, en Hurtado esta idea tiene raras apariciones. Un texto de valor secundario expresa bien un concepto diseminado en otros textos suyos y avala su comportamiento tolerante. En él se alude a una "nueva cristiandad" (60) como una realidad más espiritual que política. El P. Hurtado conoce bien el valor de las leyes. Es un católico que en la relación con Dios integra los esfuerzos de la razón

(57) William Thayer, colaborador del P. Hurtado en la Acción Católica y democratacristiano de los primeros años, sostiene: "El Padre tenía gran afecto y, a veces, admiración, por algunos falangistas, pero sin ninguna preferencia fundada en tal calidad" (W. Thayer, o.c, p. 108).

(58) W. Thayer confirma el dato: “...la ASICH nació claramente como grupo parasindical a iniciativa del P. Hurtado y no como 'Central de Sindicatos' o 'Central de Trabajadores', para lo cual se hubiera requerido razonable representatividad laboral" (o.c., p. 24).

(59) W. Thayer, o.c., pp. 60-61.

(60) S17 y 02: "Padre Aspiazu y otros. Entrevistas". 
por organizar jurídicamente la convivencia. Pero no espera de la política la sociedad a la que aspira, más que de la conversión de los católicos. Tiene una idea espiritual de cristiandad. "El principio unificador de la cristiandad no es el Papa, es el Espíritu Santo. Por su presencia por la gracia en todos los bautizados" (61). Reconoce en la jerarquía eclesiástica una presencia más fuerte de la acción del Espíritu. Es católico. Pero Hurtado experimenta ya el influjo de la teología de punta de su época. Afirma la presencia del Espíritu en los no cristianos. Y, sobre todo, alerta contra la opinión inversa: el "peligro de encerrar al Espíritu Santo en la caja de los bautizados" (62). Aun cuando el P. Hurtado no se haya explayado sobre las consecuencias de este teologumeno de la fe católica, es necesario creer que este implica la ruptura de la noción clerical de cristiandad y, en lo inmediato, guía interiormente su comportamiento. El mero hecho de ser católicos no es garantía de nada. El catolicismo burgués vale para él poco o nada. En los católicos y en los "paganos" es posible hallar al Espíritu Santo y, en su razón, hay que "discernir su presencia" (63). El P. Hurtado es un "contemplativo en acción", cuya oración consiste en escrutar la acción de Dios en los acontecimientos históricos para hacer su voluntad.

\section{LA TRANSMISIÓN TEOLÓGICA DE UNA PIETAS APOSTÓLICA}

Las secciones anteriores desembocan en la que ha podido ser la teología que el P. Hurtado ha deseado que los sacerdotes reciban, como instrumento decisivo para transmitir una experiencia de Dios capaz de cambiar integralmente a las personas y a la sociedad.

a) ¿Hurtado teólogo? (64)

Parecerá un despropósito plantear la pregunta. Además de las razones argüidas más arriba, es evidente que Alberto Hurtado no fue un teólogo profesional. Pero ¿fue teólogo en algún modo? En el sentido más amplio del término, ciertamente lo fue. A todo cristiano corresponde un intellectus fidei y a los sacerdotes con mayor razón. A diferencia de muchos que tienden a eximirse de pensar la relación de la fides quae y la fides qua, Hurtado lo hace permanentemente.

No es esto, sin embargo, lo más importante de recordar. El P. Hurtado tiene un modo de entender la teología tan amplio y exigente que probablemente la mayoría de los teólogos profesionales no pasarían su examen. Su crítica a los sacerdotes remonta a la teología que han recibido como la fuente de cierta indolencia y ceguera

(61) $\mathrm{S} 17$ y 02

(62) S17 y 02.

(63) S17 y 02.

(64) Sobre la importante colaboración del P. Hurtado en la fundación de la Facultad de Teología de la P. Universidad Católica de Chile, es necesario consultar dos artículos de Samuel Fernández: "Relación del Padre Alberto Hurtado, S.J., con la Facultad de Teología de la Pontificia Universidad Católica de Chile" (Teología y Vida, Vol XLIV [2003], pp. 3-18) y "Correspondencia del Padre Alberto Hurtado C., S.J., relacionada con la fundación de la Facultad de Teología de la Pontificia Universidad Católica" (ibídem, pp 19-47). 
con que desempeñan su oficio. No se puede pasar por alto que la queja privada que el P. Hurtado dirige a Pío XII contra los obispos no apunta tanto a que se los vea del lado de los conservadores, como a una incapacidad para darse cuenta de lo que sucede (65). Pues bien, la teología que él exigirá para la formación de los sacerdotes tendría que curar de raíz este defecto. La teología, según Hurtado, debiera capacitar a los sacerdotes para "ver" con los ojos de la fe la realidad en toda su amplitud.

¿Qué es la teología? La enseñanza universitaria de esta ciencia nos desvía de la misma, si no se aceptan algunas distinciones mínimas. El concepto está en disputa, no hay duda. Pero al concebir la teología como intellectus fidei, las diversas disciplinas teológicas se acercan a su noción por analogía. La dogmática o sistemática es la disciplina teológica por excelencia, pues tiene por objeto comprender la acción histórica de Dios en Jesucristo. La historia, la exégesis y las disciplinas prácticas se subordinan a esta comprensión teológica de la actuación de Dios. El P. Hurtado no es más teólogo por haber escrito una Moral Social, por haber recibido el encargo de conseguir profesores para la Facultad de Teología y colaborar con la formación de su biblioteca, que por haber procurado desentrañar la acción y la intención de Dios en los acontecimientos de su época. Resulta paradójico, por lo mismo, que un teólogo no profesional llame al orden a los que sí lo son. Para Hurtado, una cátedra no hace a un teólogo. Si la teología no pone en contacto con Dios, con el mundo y consigo mismo, Hurtado pensaría que las desconexiones que ella produce son la prueba de su extravío. Es más, para él la teología no es inocua: "en la teología está en juego todo el hombre. Hay en ella riesgos si no se la aborda debidamente" (66). Si la teología no hace bien, puede hacer daño.

Por la misma razón que a San Ignacio otros le llamaron el "teólogo" y los primeros jesuitas gustaron de desarrollar una "teología mística", Hurtado cree hacer teología cuando poniendo a Dios ante todo piensa todo a partir de Dios. Lo que él exige de la enseñanza de la teología a los sacerdotes es lo mismo que él practica como sacerdote que reflexiona críticamente a la luz de la fe. Habla de sí mismo cuando afirma: "la teología debe abarcar la revelación entera; la vida toda a la luz de la revelación. Si esto se entendiera no se escandalizarían al oír al sacerdote al hablar de problemas contemporáneos desde el púlpito" (67). En cuanto "místico social", su hábito espiritual de percibir a Dios en el pobre de una sociedad estructuralmente injusta, constituye la dimensión contemplativa y teórica de su compromiso activo y ético por cumplir la voluntad de Dios de reformar integralmente la sociedad. En Hurtado su pasión apostólica es la locomotora de su reflexión creyente sobre la realidad; su actividad teórica cumple una funcionalidad eminentemente práctica. No cabe duda alguna que, de este modo, Hurtado anticipa los desarrollos de la teología de la liberación latinoamericana.

Para el estudio de este tema aprovechamos unas páginas de Alberto Hurtado sobre "la formación del sacerdote" (68). Este texto tiene una longitud fuera de lo

(65) S62 y 02: "Discurso a Pío XII".

(66) S40 y 11: "La formación del sacerdote".

(67) S40 y 11.

(68) S40 y 11. 
común y, no obstante algunas insuficiencias redaccionales, puede considerarse que refleja la opinión de su autor en su madurez.

El horizonte sacerdotal en el que el P. Hurtado ubica la teología científica, cualifica a esta con una neta orientación apostólica que el teólogo solo consigue mediante una vida espiritual activa y un contacto hondo con sus contemporáneos. "El sacerdote debe saber ciencia teológica, pero esta ciencia, a diferencia del derecho, matemáticas, etc., es más que pura ciencia, nunca menos, pero sí más. No es asunto de la pura inteligencia. Un teólogo fuertísimo en su ciencia pero que no habla al hombre como hombre, y no la posee como sacerdote lleno del espíritu del Evangelio no logrará llegar al hombre. Podrá en el mejor de los casos despertar la curiosidad intelectual de los otros, pero nada más ¡merecerá aprobación de erudito pero nada más!" (69). Hurtado no se deja fascinar por la cientificidad de la teología. La critica, si esta no es sabiduría que dé vida a la Iglesia y al mundo.

\section{b) Crítica a la teología escolástica}

Hurtado padeció la enseñanza de una teología muy parecida a la teología escolástica que lamentaron los primeros jesuitas. Como ellos, ha podido valorar la teología de Santo Tomás por su excelencia, por su seriedad y por su aptitud para dar a conocer la fe de la Iglesia en su integridad. En la medida que los manuales han pulverizado la visión espiritual y vital del Aquinate, sin embargo, el P. Hurtado ha clamado por una teología que él solo pudo esbozar en sus trazos generales. Hablará de esta in recto y, a la pasada, deslizará agudas críticas en contra de la teología que de hecho se enseñaba en los seminarios y las facultades.

A los profesores los critica severamente por eludir los cuestionamientos auténticos a la teología, desincentivando, con su falta de amor a la verdad, el interés de los alumnos por su estudio (70). Les reprocha la estrechez del marco de estudio de la teología. Hurtado quería que fuera más amplio, que se estudiara más teología bíblica. Lo más típico de Hurtado empero, es ampliar el horizonte de la teología de modo que responda a los desafíos históricos de la época actual. Su queja es aguda: “¿Por qué no se plantean nuestros teólogos las últimas cuestiones del hombre, de la humanidad de hoy con toda su trascendencia? ¿Por qué son tan mezquinas las explicaciones sobre la fe en los manuales?" (71). Un cambio en la materia requeriría de los profesores y teólogos una apertura interior, una exposición a los acontecimientos, una pasión por la humanidad, sin lo cual la transmisión de la teología se hace prácticamente estéril.

Con culpa o no del sistema de enseñanza, reprocha a algunos estudiantes su forma memorística e irreflexiva de estudiar. Dice a su propósito: "en teología el que

(69) S40 y 11.

(70) "No hay estudio más apasionante si se hace con seriedad. Si a algunos le disgusta hay que achacarlo a veces a los profesores de teología entre los cuales hay algunos 'tan prudentes como perezosos que se desentienden de todas las dificultades que hallan en el camino'. De este modo evitan fácilmente preguntas molestas y alejan de sí a los preguntones, pero también a los teólogos futuros... Estos pudieron aprender mucho de ellos, pero no quizás el amor a la verdad, al LOGOS" (S40 y 11).

(71) S40 y 11. 
no ha trabajado por sí mismo la materia, el que no ha descubierto su espíritu y lo ha convertido en nueva vida, no podrá comunicarlo a los otros" (72). Dirá aún: "¡Un teólogo que calienta exámenes jamás tendrá visión personal del mundo en el que va a dar testimonio, no conocerá al hombre al que va a hablar, ni sus problemas!" (73). Anima, por el contrario, a un estudio de la Sagrada Escritura que ocupe al hombre entero: "sentidos y corazón, inteligencia y voluntad... Así dará luz al entendimiento, calor al corazón, vida a la voluntad, espíritu al trabajo" (74). Hurtado concibe el estudio como una actividad espiritual. La teología constituye una etapa clave de la formación del sacerdote. $\mathrm{Y}$ el secreto de esta consiste en un conocimiento personal de Dios que se traduzca en un conocimiento de la propia persona del estudiante. Con suma inspiración afirma: "la formación debe llevar a cada uno a descubrir en sí aquel núcleo creador característico suyo, y a ponerlo en contacto con la chispa eterna" (75). Por el contrario, sigue, "el que no ha descubierto su principio creador podrá adquirir cultura, podrá asimilar ciencia, pero no podrá modelarse él mismo orgánica y armónicamente" (76).

La crítica de Hurtado contra la teología no estriba en su carácter científico, sino en su falta de vitalidad. ¿Critica un sacrificio de la subjetividad a cierta idea de cientificidad? Es probable. Consta, este dato es seguro, que la desconexión de la teología respecto de la espiritualidad, constituiría para él el origen del empobrecimiento de la teología: "teología tiene que ser más que escolástica si es ciencia viva, pues es la ciencia de Dios y la suma más alta del saber humano. El hombre la estudia no solo con su inteligencia sino con toda su alma elevada por la gracia, iluminado por el Espíritu Santo y si es del caso aun arrebatado por el fervor místico. Un concepto puramente intelectual y racional empobrecen la teología" (77).

Por la misma razón, al igual que muchos contemporáneos, Hurtado reclama a la teología un retorno a las fuentes de la revelación: "La última seguridad en el juicio, el verdadero guía en todas las circunstancias de la vida nos ha de venir de una viva orientación en la Palabra de Dios. El que no bebe inmediatamente en las fuentes; el que se contenta con un trato superficial con la Escritura está perdiendo el contenido de la Revelación. La Teología debe ser ante todo un trato profundo y personal con la Palabra de Dios; un beber dicha palabra en la Escritura y en la Tradición" (78). Algo semejante enseñará Dei Verbum no muchos años después.

\section{c) Una teología para la conexión con el mundo}

La pietas no basta. La pietas apostólica tampoco es suficiente, si ella no es ilustrada intelectualmente. En el otro extremo, una eruditio teológica rica en elucubraciones o fundamentaciones a pie de página, pero desvinculada de una experiencia espiritual, vinculada a una experiencia espiritual estrecha y, amén de esto o aquello, 
eximida de pertinencia histórica, también extravía a los sacerdotes de su misión. Es característica de Hurtado exigir la mediación permanente de ambas y, además, de concebir espiritualidad y ciencia con mayúsculas. En este campo la ambición de Hurtado es teo-lógica en sentido estricto. Tanto la pietas como la eruditio que requiere han de ser omnicomprensivas.

Sabemos que la mística consiste en una experiencia sublime de unión con Dios. En la medida que esta es una experiencia cristiana de Dios, en vez de sacar del mundo (como hace la contemplación de cuño griega), encarna en el mundo. Esta es la lógica inaugurada por el Verbo hecho carne. De aquí que, dice el santo jesuita, "la teología debe ponerse en contacto con su época" (79). En la experiencia mística los cristianos aman a Dios amando el mundo creado por Dios. En virtud de una experiencia de unión con Dios mediada por la realidad creada e histórica más amplia, Hurtado pide de la teología una multiplicidad de contactos que ella solo puede cumplir en línea de máxima. La teología podría favorecer tal experiencia. Hurtado probablemente habría llamado a la suya, "teología de la conexión".

En primer lugar y como condición de posibilidad de todo lo demás, Hurtado exige a la teología un contacto con Dios mismo. La unión con Dios constituye el factor clave de cualquier comprensión auténtica de la realidad y de Dios mismo. Ella es el objeto fundamental del saber universitario y, por de pronto, de la teología. Esta debe nutrirse del contacto con Dios, debe pensarlo y favorecerlo. De otro modo yerra el tiro.

Pero la unión con Dios del teólogo solo puede traducirse en una teología relevante, salvífica o liberadora diríamos hoy, si ella expresa la unión del sujeto consigo mismo y la unión con su mundo. No es evidente que un cristiano viva en contacto con su propia persona. Tantos que son cristianos de nombre viven irreflexivamente su fe. Hurtado pasa el aviso: "El mensaje de Cristo en todo lo que se refiere a mí personalmente y a mis cuestiones íntimas es materia de teología" (80). Ocurre a menudo, por otra parte, que la espiritualidad desconecta al cristiano del mundo cambiante en el que vive, remitiéndolo a tiempos y espacios protegidos que se definen como sagrados. Hurtado pide a la teología todo lo contrario: "Toda dogmática y toda moral deberían tener un espíritu vuelto hacia Dios y hacia el mundo. Por eso si Santo Tomás escribiera hoy su Suma la haría muy distinta en los problemas a que se referiría" (81). En contra de una teología para cualquier tiempo y lugar, la unión con Dios reclama a la teología una pertinencia personal y epocal.

Al P. Hurtado no bastaría que la unión con Dios se verificara exclusivamente en un contacto personal con Él, humanizante y/o reconciliador. El pietismo intimista no cabe en su concepción de la unión cristiana con Dios y de su idea de la teología. Pero, por otra parte, una verificación meramente social de la unión con Dios, imaginada como un cambio de estructuras económicas prescindente de la conversión del corazón, sería para él una ilusión de corto alcance. Ni pietismo intimista ni pietismo socializante. Hurtado denuncia ambas fugas, la del cristianismo puertas adentro de 
la iglesia y la del cristianismo que compromete a la acción social pero que no vive de Cristo. El encuentro con Dios en la propia alma y en la reforma social estructural que anticipa el reino de Dios, son realidades irreductibles e inconfundibles. Pero solo verifican una auténtica unión con Dios cuando se orientan una a la otra y cuando se compenetran recíprocamente (82).

De varias maneras demanda una teología viva. El teólogo debiera esforzarse por desentrañar la vida que encierra el dogma. La historia de cada uno de los dogmas puede, según él, ser revivida. "El teólogo tiene que seguir siendo niño, tiene que conservar la reverencia y admiración del niño" (83), afirma. Para lo cual será necesario, insiste, volver a las fuentes de la Palabra y de la experiencia de Dios.

Una visión tal de la unión con Dios y de su necesarias mediaciones, supone en Hurtado una teología de la revelación rica en perspectivas. Al centro de esta, siempre y sin poder dudarlo, se encuentra Cristo como la revelación máxima de Dios. La teología del Cuerpo de Cristo que suministra a Hurtado una visión solidaria de la Iglesia y de la humanidad, se da la mano con una teología del Logos que hace concebible la revelación natural de Dios a través de la creación y de la razón humana. Alberto Hurtado reclama de la teología la universalidad que la escolástica de los manuales le ha quitado. Una y otra vez, la crítica parece dirigirse contra un tipo de teología estrecha y mortecina. Pide, por su parte, una teología que "abarque todo el mundo y en la cual tenga su valor y rango todo lo creado" (84).

Así las cosas a Hurtado no le cuesta mucho aceptar las mediaciones culturales. Las demanda. Aunque nada supera la revelación paradójica de Dios en la cruz, las diversas disciplinas científicas pueden efectivamente facilitar la comprensión de la sociedad en vista a convertirla en un "orden social cristiano".

De aquí que el sacerdote deba ser culto, conocer su época y su tiempo. Ya esos años, Hurtado advierte que el sacerdote no puede descansar en su estado, sino saber que los demás lo valorarán por su superioridad humana y espiritual. La teología no basta. Ella tiene un lugar clave al interior de una formación sacerdotal que necesita además otros saberes. "El sacerdote ha de estar abierto a todas las inquietudes del espíritu humano: literatura, arte, historia, filosofía, finanzas, teatro, deporte, poesía... Debe estar abierto a la vida y a todas sus manifestaciones porque debe santificarlas todas" (85). El sacerdote ignorante, en cambio, es un peligro (86).

(82) Cf. Humanismo Social, o.c., pp. 89 y 179.

(83) S40 y 11.

(84) S40 y 11. “...una teología universal está en relación íntima con los anhelos y necesidades más profundas del hombre" (S40 y 11).

(85) S40 y 11. "El sacerdote que comprende la ejemplaridad universal del LOGOS encontrará una huella de Él en todo: arte, cultura, ciencia, economía, y en cada alma humana 'naturaliter christiana'; por eso no se encierra ante ningún valor y cualquiera que sea su envoltura descubre en ella la verdad cristiana que nosotros dejamos volverse loca. Como lo hiciera Agustín, Cipriano, Lactancio... hay que tomar aun de entre los paganos lo que es nuestro, a pesar que ellos lo reclamen como de ellos. Dialéctica, Retórica, Matemáticas, Historia, Geografía, Arte... Si es verdadero, si es en verdad bello y bueno es nuestro. Esto se deduce del concepto de LOGOS = Verdad, bien, belleza. (Aplicación al existencialismo, reacción ante manuales secos)" (S40 y 11).

(86) Cita a San Francisco de Sales: "Necesidad de formación: 'Es más de temer en un sacerdote la ignorancia que el pecado. Si Ginebra (Calvino) ha causado tan terribles devastaciones se debe a que nosotros estuvimos dormidos y nos limitamos a rezar nuestro Breviario, sin que hubiéramos pensado en acrecentar nuestra ciencia"” (S40 y 11). 


\section{d) Idea de la universidad}

La idea de universidad de Alberto Hurtado es afín a su concepto de la teología. A ella se refiere directamente o a propósito de los profesores y alumnos universitarios. Si la cuestión social no es objeto estricto de su preocupación por la enseñanza teológica, sí constituye un motivo determinante de su visión del quehacer universitario.

Hurtado esgrime una crítica contra la universidad. Su queja se centra en la formación de meros profesionales (87). Tienen culpa de esta profesores carentes de visión de conjunto: "En muchas cátedras, sobre todo en las más técnicas, hay el peligro que el profesor se considere el especialista y nada más, y dé su ramo con total abstracción del conjunto de la enseñanza y sin colaborar armónicamente a obtener el ideal universitario" (88). En otro plano lamenta la mala calidad de la enseñanza universitaria estatal y reclama del Estado libertad para que sea verdaderamente posible una enseñaza universitaria católica (89).

No hay que buscar en Hurtado una definición técnica de la misión de la universidad. Pero entre los mejores párrafos que dedica a esta evidencia un concepto rico, clásico y moderno a la vez. Afirma: "la Universidad debe ser el cerebro de un país, el centro donde se investiga, se planea, se discute cuanto dice relación al bien común de la nación y de la humanidad. Y el universitario debe llegar a adquirir la mística de que en el campo propio de su profesión no es solo un técnico, sino el obrero intelectual de un mundo mejor" (90).

Cabe preguntarse si el carácter católico o cristiano de una universidad corresponde a esta por la fe subjetiva de sus miembros o por la naturaleza del saber que cultivan las facultades y escuelas. Es algo temerario responder a una pregunta que Hurtado no se hace. Con todo, es importante incursionar en la dirección de su pensamiento. He aquí que ambos aspectos están presentes en su discurso universitario. Para él, la universidad se debe derechamente a la transformación de la sociedad en perspectiva social y de bien común, pero esto no lo logrará sino a través de personas formadas integralmente y capaces de una visión de conjunto. "La Universidad ha de formar hombres, antes que todo. Hombres, no archivos ambulantes ni grandes eruditos. La actitud principal del profesor ha de ser la de dar una visión de

(87) “...hoy la Universidad solo forma profesionales, que al salir a poner en práctica los conocimientos tan trabajosamente adquiridos fracasan ruidosamente" (S22 y 25: "Los estudiantes católicos y las reformas universitarias").

(88) S40 y 09: "Profesores universidad católica".

(89) "La docencia libre, la representación del alumnado en los consejos de profesores y la autonomía universitaria, para producir benéficos resultados deben actuar en un medio de mayor libertad y tolerancia. Dentro de las ideas que informan actualmente la instrucción pública en Chile, que están dominadas por un feroz sectarismo estas reformas no producirían los resultados apetecidos. Hay que ir, pues, a la libertad universitaria; es necesario que el proyecto de que es autor el viejo luchador de la causa católica don Abdón Cifuentes sea transformado en ley. La competencia que se entablaría entre universidades reconocidas por el Estado y que con igual derecho podrían expedir sus títulos sería enorme. Los alumnos y el público serían los mejores jueces: los primeros eligiendo los buenos profesores, los segundos empleando los mejores profesionales.

Es de esperar que los pésimos frutos de la enseñanza oficial terminen por abrir los ojos a los que aun resisten estas ideas, y sea una realidad la universidad libre" (S22 y 25).

(90) S40 y 07: "Misión del universitario". 
conjunto. No un mero hábito, sino una visión de conjunto. La Universidad debe dar ese hábito hacia la verdad. Sabiduría no es erudición. La mera erudición es pesada, amontona ladrillos como una fábrica" (91).

Con estas últimas palabras Hurtado empalma la formación de personas con la necesidad de un tipo de desarrollo científico universitario específicamente cristiano. No es cuestión de la universidad formar personas caritativas. Esto también lo hacen otros. Por ser cristianos y universitarios al mismo tiempo, profesores y alumnos cumplen una tarea que solo ellos pueden llevar a efecto. A saber, "la caridad del universitario debe ser primariamente social: esa mirada al bien común. Hay obras individuales que cualquiera puede hacer por él, pero nadie puede reemplazarlo en su misión de transformación social. De aquí cada uno en su profesión orientada a su misión social" (92). Esto implica una formación mucho más amplia de la que normalmente exige cada carrera (93).

Es evidente que Hurtado espera de los católicos un rol protagónico en las universidades, su fe debiera movilizarlos intelectualmente en favor del bien común. Pero no excluye, antes correspondería suponer que, siendo tal la misión, también otros no católicos pudieran intentar esta misión, para lo cual rige por parejo la obligación de capacitarse con una formación humana lo más amplia posible.

En medio de la sociedad la universidad cumple una función pensante, pero también agitadora. Lejos está Hurtado de exigir de ella un rol meramente pacificador. Sus palabras son estremecedoras: "la universidad ha de mantener vivo en el alumnado el sentido del inconformismo perpetuo ante el mal y ha de alentarlo a protestar con los hechos, con la voz, con la pluma... y cuando otra cosa no puede, al menos en el fondo de su conciencia". Continúa su discurso a universitarios: "no depende de nosotros el que una masa enorme de gentes continúe mal alimentada, mal alojada... pero al menos no tratemos de pactar con el mal, no nos acostumbremos, seamos la voz permanente de la justicia" (94).

Hurtado conserva la idea clásica de universidad y aboga por ella. La universidad se debe a una verdad una y universal que tiene en Dios su razón última de ser. Por ello no puede concebirla sin una facultad de teología, la primera de las ciencias. Sus palabras pueden levantar sospechas de intolerancia religiosa: "no podrá haber jamás universidad de ciencias sin facultad de teología, ni facultad universitaria sin

(91) S40 y 09. En otro lugar afirma: "Llegar a esta visión integral de la vida, la primera que ha de comunicarse, y a una especialización en mi ramo, pero encuadrada dentro de ese plan, es la misión de la Universidad, misión que se ha de realizar en cada Facultad, y hasta en cada asignatura" (S40 y 9). La misión de la universidad se desliza a la del universitario: "La misión del universitario es la del estudioso que traduce esos ideales grandes del hombre de la calle en soluciones técnicas, aplicables, realizables, bien pensadas. Hacerlo es la mayor obra de caridad que puede hacer un hombre, pues es la caridad social, pública" (S08).

(92) S22 y 24: "Lo que ha de despertar la universidad en sus alumnos".

(93) "Cada uno debe conocer el problema social general, las Doctrinas Sociales que se disputan el mundo, sobre todo su Doctrina, la doctrina de la Iglesia, debe conocer la realidad chilena y debe tener una preocupación especial por estudiar su carrera en función de los problemas sociales propios de su ambiente profesional. Círculos de estudios sociales especializados por carrera, para realizar el ideal de Pío XII: elemento substancial del orden nuevo: elevación (del) proletariado" (S56 y 22: "La misión social del universitario").

(94) S08. 
la ciencia de Dios..." (95). Pero Hurtado está lejos del integrismo, pues su propia teología le permite captar la articulación virtuosa de la revelación de Dios a través de la historia de la salvación cristiana y a través de la creación entera. Es esta percepción aún más honda de la realidad la que subyace a estas otras palabras en las que no ve incompatibilidad, sino necesaria vinculación y compenetración, entre la teología y las demás ciencias universitarias: "Los dos métodos: el experimental (inductivo y analítico), y el teológico (de autoridad y deductivo), ; con cuánta frecuencia se miran con recelo... y se anatemizan no en virtud de principios basados en la ciencia criticada, sino en prejuicios de la propia...! Que no anatematicen. Que tengan respeto y simpatía por la otra ciencia. Que sepan que verdad no se opone a verdad. Que o el dogma es mal entendido o la conclusión científica no lo es” (96).

¿Pensó Hurtado que la universidad debía primordialmente hacer de Chile un país católico? Tampoco se hizo esta pregunta, al menos no con las implicancias que a lo largo de este artículo hemos venido desarrollando. Los textos indican con claridad que el objetivo de la universidad es edificar un país justo. A la luz del contexto se puede inferir que, en la medida que una universidad cristiana cumpliera este objetivo, indirectamente haría de Chile un país católico, pero que este fin desquiciaría la razón de ser de la universidad si se intentara en perjuicio del anterior.

\section{CONCLUSIÓN}

A Alberto Hurtado le faltó una comunidad intelectual de pares. En nuestro medio y probablemente esos años, debió ser difícil encontrarla. Una comunidad académica como la de la actual Facultad de Teología que se reúne cada dos semanas para su seminario interno, habría exigido a Hurtado corregir sus textos, suministrándole a la vez sugerencias que ciertamente habría integrado. Sus escritos habrían tenido mayor rigor y mejores terminaciones (97). Hurtado no tuvo esta posibilidad.

(95) "Y la primera ciencia que ha de enseñar una universidad católica es la teología, la ciencia de Dios, la primera y suprema realidad, y por tanto la primera ciencia... Dios es por lo mismo el objeto primero y supremo de la ciencia, de suerte que toda otra ciencia en comparación con la ciencia de Dios es una vanidad, una sombra de la gran realidad, sombra parcial... En este punto los católicos no podemos transigir: no podrá haber jamás universidad de ciencias sin facultad de teología, ni facultad universitaria sin la ciencia de Dios, como no puede haber año sin primavera, ni Hamlet sin el papel de Príncipe de Dinamarca. Quitad a Dios del conjunto de las realidades y tendréis un mapa de la tierra, sin tierra firme" (S40 y 09).

(96) S40 y 09. En otro lugar afirma: "La teología como tal es teoría. Debe hacerse viva. Se hace viva cuando se pone en relación con la realidad concreta, con el arte, con la ciencia, con la literatura, con las corrientes espirituales de la vida. El teólogo que no esté familiarizado con la plenitud de las manifestaciones del LOGOS en la vida construirá castillos en el aire. Su tarea consiste en fecundar los esfuerzos del espíritu humano con la levadura del Evangelio" (S40 y 11).

(97) El mismo Alberto Hurtado fue consciente de los límites de su escritura. En carta de respuesta a las críticas que Carlos Aldunate le representa, Hurtado reconoce las dificultades de redacción de Humanismo Social y pide comprensión. Sus propias palabras reflejan bien las circunstancias de su actividad intelectual: "En cuanto a lo que me dice de Humanismo Social trasmitiéndome el testimonio de un buen amigo: estoy muy de acuerdo en la redacción descuidada (¡no soy escritor!); quizás algunos datos que no concuerdan. Yo agregaría otras críticas; mucha falta de originalidad; demasiada citación; no es obra de aliento; es vulgarización. Ciertísimo. ¿Libro muy apurado? Hasta cierto punto: en los retoques de redacción, sí: pero en "apreciaciones apresura- 
No siguió tampoco una carrera académica. Se comportó como un intelectual católico solitario, algo francotirador, que trató de establecer un diálogo informado con la Iglesia y la sociedad. No se puede obviar, empero, que sus libros se vendieron y merecieran una segunda edición. ¿Qué académico puede decir lo mismo? Lo que tuvo que decir, algún eco encontró entre sus contemporáneos.

Me atrevo a decir que el legado intelectual de Hurtado tiene que ver más con la forma que con el contenido. Tengo la impresión de que la originalidad de su aporte dice relación más con su modo de pensar que con las conclusiones a las que llegó. Para ser recuperado hoy, su pensamiento tendría que experimentar una importante puesta al día. Gran parte de su actividad la dedicó a difundir el pensamiento social de la Iglesia, aunque lo hiciera con vitalidad, con conexiones inteligentes y con imágenes novedosas. Por esto su influjo en la reflexión social católica chilena y latinoamericana ha sido notable. ¿Cuánto marcó Hurtado en los últimos cincuenta años la dirección de la revista Mensaje? ¿Cuánto pudo influir en Mons. Larraín y, por medio de este y otros obispos chilenos, en la recepción que Medellín hizo del Concilio Vaticano II? Ciertamente mucho.

Pero en la forma de pensar, en el modo de ser intelectual, Hurtado conserva para nosotros hoy una enorme vigencia. Vistas las cosas en perspectiva, cuando el catolicismo mundial experimenta una crisis mayor, cuando por primera vez en la historia se abre la posibilidad de un catolicismo latinoamericano, cuando es cada vez más difícil depender teológicamente de Europa porque las grandes familias de teólogos europeos (franciscanos, benedictinos, dominicos y jesuitas) han menguado dramáticamente, la necesidad de volver a conectar la eruditio con la pietas correspondiente a los nuevos tiempos, conexión que Hurtado representa, tiene una actualidad máxima. Hasta aquí hemos podido mostrar la índole jesuítica de la inserción de la eruditio en la pietas apostólica de Alberto Hurtado. En esto, evidentemente, él no es para nada original, aunque en nuestro medio chileno y eclesiástico activista y tantas veces antiintelectual, haya sido novedoso que un hijo de San Ignacio desenterrara un talento escondido. La originalidad, en su caso, estriba en haber verificado su vocación de "contemplativo en la acción" como un "místico social". Si bien en esto de encontrar a Cristo en el pobre Hurtado no hace más que desenterrar un segundo talento ignaciano, lo hace, eso sí, como un hombre moderno. El pobre "en" el cual Hurtado encuentra Cristo y "para" el cual él es Cristo, es el pobre de una sociedad católica en crisis, de una sociedad injusta y que, en consecuencia, puede y debe ser estructuralmente reformada.

Hurtado representa un llamado de atención a los teólogos y a las universidades. A ambos exige preguntarse cuáles son sus cables a tierra. ¿A qué experiencias de los hombres y de las mujeres de hoy, a qué crisis de humanidad, han dedicado la

das", no creo: lo vengo pensando y preparando más de dos años. Es el fondo de lo que he predicado durante este tiempo". Continúa más adelante: "Es juzgar según un principio abstracto, general, un caso concreto sin ver sus circunstancias. Esas normas claro está son muy válidas, puede ser que el libro juzgado merezca en absoluto esa apreciación. ¿Pero ha pensado quién lo ha escrito, en qué condiciones de actividades, de tiempo, de preparación? Lo que sería válido para un escritor de Études, ¿lo es para un hombre que tiene diez cosas a la vez? Dirá: entonces ¿para qué escribe? Porque cree que a pesar de todo hay un público al cual aun esa manera imperfecta, pobre, sirve y aprovecha" (S62 y 059). 
investigación? ¿Para qué investigan? ¿Para quiénes? ¿Quién piensa para los más pobres, los últimos en la sociedad y en la Iglesia? Hoy, cuando los vínculos entre la universidad y las grandes empresas son cada vez más poderosos, Hurtado recordaría a los universitarios católicos que la integración de fe y ciencia a la que las universidades se deben como a su fin específico solo tiene sentido cuando sirve a la integración de fe y justicia.

\title{
RESUMEN
}

En Chile Alberto Hurtado es conocido como un hombre extraordinario por su amor a los más pobres. Este artículo subraya que el santo chileno fue un intelectual típicamente jesuita, aspecto de su personalidad bastante desconocido. Hurtado relacionó pietas y eruditio en vista del cambio social que la Iglesia quiso impulsar a lo largo del siglo XX. El pobre en quien Hurtado encontró a Cristo fue el pobre víctima de una sociedad estructuralmente injusta. Su santidad consiste en haber acudido a su redención con la caridad pero también como uno de los intelectuales principales del catolicismo social chileno.

\begin{abstract}
In Chile, Alberto Hurtado is known as an extraordinary man because of his love for the poorest. This article emphasizes how the Chilean saint was a typically Jesuit intellectual, a fairly unknown aspect of his personality. Hurtado related pietas and eruditio in view of the social change that the Church wanted to promote throughout the $20^{\text {th }}$ century. The poor person, in whom Hurtado found Christ, was the impoverished victim of a structurally unjust society. His holiness consisted in having attended to his redemption with charity, but also as one of the principal intellectuals of Chilean Social Catholicism.
\end{abstract}

